جامعـة نيويورك أبـوظـبي

$\stackrel{\uplus}{i}$ NYU $\mid$ ABU DHABI

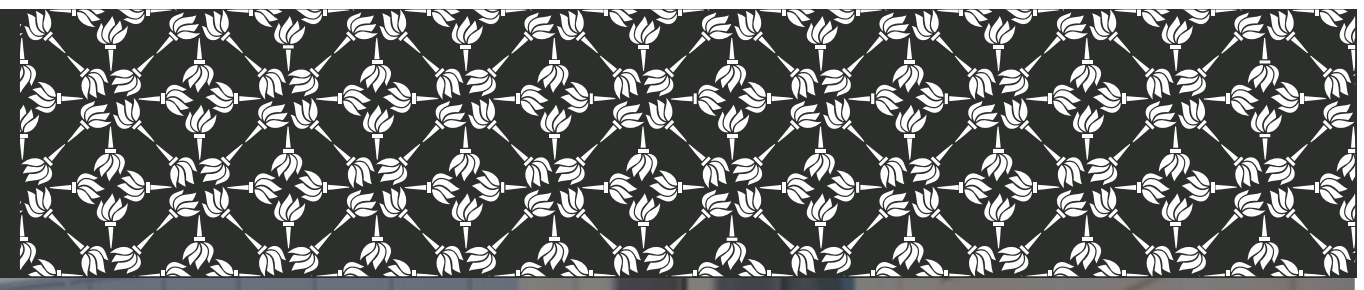

\title{
Asset price volatility and investment horizons: An experimental investigation
}

\author{
Mikhail Anufriev, Aleksei Chernulich, Jan \\ Tuinstra
}

Working Paper \# 0053

August 2020 


\title{
Asset price volatility and investment horizons: An experimental investigation*
}

\author{
Mikhail Anufriev ${ }^{\mathrm{a}, \dagger}$ \\ Aleksei Chernulich ${ }^{\mathrm{b}, \sharp}$ \\ Jan Tuinstrac ${ }^{\mathrm{s}} \S$ \\ 17 August 2020
${ }^{a}$ University of Technology Sydney, Business School, Economics Discipline Group
b New York University Abu Dhabi, Division of Social Science
c University of Amsterdam, Amsterdam School of Economics, CeNDEF

\begin{abstract}
We study the effects of the investment horizon on asset price volatility using a Learning to Forecast experiment. We find that, for short investment horizons, participants coordinate on self-fulfilling trend extrapolating predictions. Price deviations are then reinforced and amplified, possibly leading to large bubbles and crashes in asset prices. For longer investment horizons such bubbles do not emerge and price volatility tends to be lower. This is due to the fact that, for longer horizons, there is more dispersion in participants' forecasts, and participants extrapolate trends in past prices to a lesser extent. We also show that, independent of the investment horizon, if the initial history of asset prices is already relatively stable before participants start their prediction task, price volatility remains small, with prices close to their fundamental values for the duration of the experiment.
\end{abstract}

Keywords: Experimental Economics, Expectations, Asset Pricing, Investment Horizons, Behavioral Finance.

*We thank David Goldbaum, Anita Kopányi-Peuker, Joep Sonnemans, and participants at the 2018 BEEF workshop at the University of Sydney, the 2018 BEAM-ABEE workshop at the University of Amsterdam, the IMEBESS 2019 meeting in Utrecht, the 2019 Asia Meeting of the Econometric Society at the Xiamen University, and the WEHIA 2019 workshop in London, for useful comments. The authors acknowledge financial support from the Australian Research Council's Discovery Projects funding scheme (project number DP140103566) and from the ORA project "BEAM" (NWO 464-15-143) which is partly financed by the Netherlands Organization for Scientific Research (NWO).

${ }^{\dagger}$ E-mail: Mikhail.Anufriev@uts.edu.au.

${ }^{\ddagger}$ E-mail: Aleksei.Chernulich@nyu.edu.

$\S$ E-mail: J.Tuinstra@uva.nl. 
JEL Classification: C91, G12, G14, G41. 


\section{Introduction}

The extent to which asset prices can be characterized by persistent deviations from fundamental values and excess volatility continues to spark the debate on the functioning of financial markets. This debate has spawned a sizable literature in experimental and behavioral finance. In particular, in laboratory experiments with paid human subjects, mispricing, as well as bubbles and crashes, are robust features (see Palan, 2013 and Hommes, 2011 for overviews). In these experiments, the participants' investment or forecasting horizon is typically given. However, in the existing behavioral finance literature, deviations from fundamental values have often been associated explicitly with short-horizon speculative trading. ${ }^{1}$ Combined with the observation that many decisions of institutional investors are driven by short-term gains, possibly at the expense of earnings in the long-run, ${ }^{2}$ several measures have been suggested to curb this so-called 'short-termism', see, e.g., Bolton and Samama (2013), and Crouzet et al. (2020).

This paper aims to better understand the effect of the investment horizon on excess volatility and the emergence of bubbles and crashes. For this purpose we study experimentally the impact the investment horizon has on forecasting asset prices. We design and run a so-called 'Learning to Forecast' (LtF) laboratory experiment, where participants act as professional forecasters for hypothetical institutional investors. ${ }^{3}$ Participants submit forecasts of the future price of an infinitely lived risky asset, for at least 50 consecutive periods, and are rewarded according to their forecasting accuracy. Each period the experimental software uses these forecasts to determine the institutional investor's optimal demand for the asset and the resulting market clearing price. The self-referential nature of fi-

\footnotetext{
${ }^{1}$ De Long et al. (1990), for example, argue that irrational noise traders may create mispricing that cannot be arbitraged away by rational traders that are limited by a short trading horizon. Similarly, Dow and Gorton (1994) argue that traders will not act upon private information if their investment horizon is too short for this information to affect prices, thus preventing the correction of mispricing. See also Froot et al. (1992) and Allen et al. (2006) for related models that argue that short investment horizons are conducive to mispricing. Cella et al. (2013) and Cremers and Pareek (2015) provide empirical support for such a relationship.

${ }^{2}$ See Bushee (2001), for empirical evidence, and Bolton et al. (2006), for a theoretical explanation.

${ }^{3}$ The main advantage of the Learning to Forecast experimental design, which was introduced in Marimon et al. (1993), is that it allows the experimenters to obtain clean data on participants' forecasts in an environment with expectations feedback. A potential drawback is that participants' forecasts might not be consistent with their behavior if they would be allowed to trade actively. However, Bao et al. (2013) and Bao et al. (2017) demonstrate a similarity of the outcomes of LtF experiments with the outcomes in 'Learning to Optimize' experiments, where participants trade. Also, note that empirical studies by Amromin and Sharpe (2014) and Greenwood and Shleifer (2014) show that survey expectations can explain portfolio choices to a large extent.
} 
nancial markets, where expectations of future prices are an important determinant of market prices, is explicitly taken into account in such an experiment. Furthermore, there is a positive feedback link between forecasts and prices: an expected future increase in the price of a stock increases the demand for that stock and, consequently, the market-clearing price as well.

In our experimental design, we vary the investment horizon of the institutional investors and, as a consequence, the forecasting horizon of the participants. Depending on the treatment, participants have to predict, at the beginning of period $t$, the price for either period $t+1$, period $t+2$, or period $t+3$. The variation in the investment horizon is our first treatment variable. Apart from a possible behavioral impact, the change of horizon also affects the market clearing equation. The discount factor decreases for longer horizons, or, in other words, the strength of the expectations feedback becomes weaker. To control for this effect in comparing different investment horizons, we add a treatment that compensates for the decrease in feedback strength. Our second treatment variable is the initial price history. Before participants start their prediction task, they observe ten previous prices, and in some treatments this price history is more volatile than in other treatments. ${ }^{4}$ This treatment variation allows us to study the effect of the initial history on price volatility. Importantly, in all our treatments, there is the same rational expectation equilibrium with a constant 'fundamental' price augmented by small, unpredictable noise.

We find that, in the treatments with an initial price history that is relatively stable, price volatility remains small until the end of the experiment, with prices staying in the vicinity of their fundamental values. Fluctuations in asset prices are much larger in the treatments with a more volatile initial price history. Moreover, these fluctuations tend to decrease with the investment horizon, even after correcting for the lower feedback strength for longer horizons (although the picture is blurred somewhat by the substantial heterogeneity between groups in the same treatment). In particular, large bubbles and crashes only emerge for the shortest possible investment horizon. ${ }^{5}$ Therefore, we show experimentally that the fore-

\footnotetext{
${ }^{4}$ In many LtF experiments - where participants typically start with a blank slate - there is a substantial heterogeneity between groups in the same treatment (see, e.g., Hommes et al., 2005 and Kopányi et al., 2019). Anufriev and Hommes (2012a,b) explain the LtF experimental outcomes by the Heuristic Switching Model (HSM) that generates path-dependent results. Therefore, the between-groups heterogeneity in the LtF experiments can be a consequence of the different price dynamics that endogenously occurred in the first few periods of the experiments. To the best of our knowledge, our LtF experiment is the first that controls for initial price dynamics.

${ }^{5}$ Note that the effect of the investment horizon does not require limits to arbitrage for participants with shorter investment horizons, as in De Long et al. (1990) or Dow and Gorton (1994). In particular, the information asymmetries between traders, assumed in these papers
} 
casting/investment horizon affects volatility, even when the rational expectation equilibrium is not affected.

In previous LtF asset pricing experiments, characterized by short investment horizons and the absence of an initial price history, large bubbles and crashes often emerge, with prices regularly exceeding their fundamental values by one order of magnitude, see, e.g., Hommes et al. (2008) and Hommes et al. (2020). ${ }^{6}$ Our results suggest that short investment horizons are a necessary condition for the emergence of such bubbles, and that even then they are unlikely to occur if the market has a history of relatively stable prices.

Looking for the reasons of the impact of the investment horizon on price volatility, we turn to the forecasting strategies of participants. We find that the large bubbles that emerge for a short investment horizon can be attributed to participants coordinating on a trend extrapolating prediction strategy. An increase in prices then leads all participants to expect a further price increase which, due to the positive feedback nature of the asset pricing model, leads to higher prices, confirming participants' expectations. There appear to be two explanations for the decrease in price volatility for longer horizons. First, participants have a much stronger tendency to extrapolate trends over shorter investment horizons than over longer horizons. ${ }^{7}$ Second, participants fail to coordinate their expectations: dispersion of individual forecasts is typically higher when the investment horizon is longer. This inhibits the emergence of large self-confirming deviations from the fundamental value. ${ }^{8}$

We contribute to the growing experimental literature on forecasting behavior along two dimensions by studying: the effect of 'priming' participants by manipulating the initial price history and the effect of the forecasting horizon by changing it between treatments. In almost all earlier LtF experiments participants start without any information about previous prices. Recently, Hennequin (2019) studied the effect of experience in an LtF experiment consisting of two phases. In the first phase, each participant is matched with five 'robot' traders,

and responsible for creating arbitrage opportunities, are absent in our experimental framework.

${ }^{6}$ Persistent oscillations of endogenous variables around their steady-state values also occur in LtF experiments with standard New Keynesian macroeconomic models, see, e.g., Hommes et al. (2019) and Assenza et al. (2019). However, in LtF experiments where there is a negative feedback between forecasts and realized prices, such as cobweb markets, prices typically quickly converge to their fundamental values (Hommes et al., 2007, Bao et al., 2013).

${ }^{7}$ Remarkably, participants' expectations, therefore, are consistent with the empirical finding that asset returns show momentum in the short run, but revert to fundamental values in the longer run, see, e.g., Hong and Stein (1999), for a discussion.

${ }^{8}$ Related to this, Patton and Timmermann (2010), who study survey data on macroeconomic forecasts of GDP growth and inflation by private sector forecasters, find that there is much more dispersion in long-horizon forecasts than in short-horizon forecasts. 
whose predefined prediction strategies create either a stable environment, with prices staying close to the fundamental value, or a bubbly environment, with large bubbles and crashes. In the second phase, human subjects are matched in groups of six, based on their experience in the first phase. Hennequin (2019) finds that experience matters, with bubbles and crashes quickly emerging specifically in markets where all participants experienced bubbly behavior in the first phase. Our finding that an unstable initial price history induces volatile price dynamics points in the same direction. An important difference, however, is that in our experiment, participants only observe, but not experience, the price history. ${ }^{9}$

For the vast majority of LtF experiments, a short investment horizon is assumed, with participants predicting the price for either the current or the next period. We discuss two recent exceptions directly related to this paper. Colasante et al. (2020) consider an LtF experiment that lasts 20 periods, and where in each period participants have to predict both the price for the current period, and the prices for all remaining periods. ${ }^{10}$ Like in our experiment, they find that there is more dispersion in long-run expectations than in short-run expectations. However, in their experiment, realized prices only depend upon short-run expectations, and hence this larger dispersion in long-run expectations does not affect price volatility. Evans et al. (2019) develop a Lucas tree asset pricing model where trading decisions depend upon the average expected price over a finite horizon, and run an LtF experiment where they vary that horizon. They find that for longer horizons dispersion of forecasts is higher, participants rely less on the trend-following strategies, and that the price is closer to the fundamental value. These results are in line with ours, even if the underlying model is quite different and, in our model, participants make point forecasts for a specific period in the future, rather than an average forecast for several future prices. The maximal investment horizon that Evans et al. (2019) use is substantially longer than in our experiment (10 instead of 3 periods), which implies a much stronger decrease in feedback strength. Our results, therefore, strengthen those of Evans et al. (2019). We find that already a minor increase in the investment horizon can have a substantial effect upon the

\footnotetext{
${ }^{9}$ Malmendier and Nagel $(2011,2016)$ provide empirical evidence that expectations of economic agents are affected by the experiences they have during their lives, although that information is also available for those who did not experience it. This effect is sometimes called the experiencedescription gap (see Hertwig et al., 2004). Kaufmann et al. (2013) and Bradbury et al. (2015) investigate this experience-description gap for investment decisions, by allowing participants to gain experience by simulation.

${ }^{10}$ This setup is similar to the approach sometimes taken in experimental asset markets, where participants - besides trading the asset - also have to forecast market prices. Haruvy et al. (2007), for example, consider an experimental asset market that lasts for 15 periods, and at each period, participants have to predict market prices for all of the remaining periods. These authors also find (in particular for inexperienced subjects) that dispersion in long-run expectations tends to be higher than in short-run expectations.
} 
ensuing price dynamics. Moreover, this result holds even when we correct for the decrease in feedback strength.

Finally, results of our LtF experiment can be compared with experimental markets where participants trade. Hirota and Sunder (2007) and Hirota et al. (2015), for example, distinguish long-horizon traders, who can trade in the asset until it reaches maturity and pays out its dividend, and short-horizon traders, who leave the market before the asset matures and can therefore only profit from speculating on capital gains. Under rational expectations, these short-horizon traders should also understand, by using backward induction from the period of maturity of the asset, that its price should equal the fundamental value (see, e.g., Tirole, 1982, 1985). However, in the experiments short-horizon traders contribute substantially to mispricing and bubbles. Although this result is similar to our finding, in our experimental design (with an infinitely lived asset) incentives for participants are the same for different investment horizons. Finally, Razen et al. (2017), who also consider trade in an asset with a single dividend that is paid out when the asset reaches maturity, find that an increase in the date of maturity (i.e., the trading horizon) may lead to bubbles. The authors attribute this to the dividend payment becoming less salient when the asset matures later.

The remainder of the paper is organized as follows. The next section presents the experimental design and the hypotheses. Results are discussed in Section 3 and Section 4 concludes. Experimental instructions, statistical tests and additional data analysis can be found in the appendices.

\section{Experimental Design}

The experiment took place at the University of Technology Sydney's Behavioural Lab in May, August, and September 2018. Using the Online Recruitment System for Economic Experiments (Greiner, 2015), we recruited 210 students who participated in seven experimental treatments. No student participated in more than one session. At each session, participants were randomly divided into groups of six that operated in the same market during the whole experiment. The experimenter read the instructions aloud (participants had printed copies of the instructions as well), after which participants did a short quiz that tested their familiarity with the task. Once all participants completed the quiz, the computerized experiment, programmed in z-Tree (Fischbacher, 2007), took place. After the experiment, participants filled in a questionnaire and received payment under the double-blind protocol. Sessions lasted approximately 80 minutes, and participants earned on 
average 27 Australian dollars, including a show-up fee.

In the remainder of this section, we introduce the price generating mechanism used in our LtF experiment (Section 2.1), discuss our experimental treatments (Section 2.2), and outline the main hypotheses (Section 2.3).

\subsection{Price forecasts and market prices: the price generating mechanism}

Our experiment is based on the standard LtF setup, see Hommes (2011) for an overview. These experiments use the standard present value model of asset pricing, see, e.g., Campbell et al. (1997), micro-founded and extended for heterogeneous beliefs in Brock and Hommes (1998). The model considers institutional investors that are myopic mean-variance maximizers and have to divide their wealth between a risky asset, with price $p_{t}$ and an IID dividend with mean $\bar{y}$, and a risk-free asset, with fixed gross return $R=1+r>1$. The dividend process is common knowledge. The original model assumes that all traders have an investment horizon of one period, but we generalize this model by allowing for longer investment horizons. Appendix A presents this general model.

Demand for the risky asset in period $t$, from an investor $i$ with investment horizon $H$, will be determined by the investor's price forecast $p_{i, t+H}^{e}$ for period $t+H$. In this paper we will consider the situation where all investors have the same investment horizon $H$. In this case, the market-clearing price is given by

$$
p_{t}=p^{f}+\frac{1}{R^{H}}\left(\bar{p}_{t+H}^{e}-p^{f}-\varepsilon_{t}\right)
$$

where $\bar{p}_{t+H}^{e}=\frac{1}{N} \sum_{i=1}^{N} p_{i, t+H}^{e}$ is the mean prediction for the price in period $t+H$, averaged over the $N$ investors in the market, $\varepsilon_{t}$ is a small random outside supply of the asset from noise traders, with mean zero, and $p^{f}=\bar{y} / r$ is the fundamental value of the risky asset. The fundamental value is equal to the discounted expected value of all future dividends and corresponds to the rational expectation equilibrium. Indeed, if all traders predict the fundamental price, the realized price will be equal to $p^{f}$ and forecasts will be correct, on average. Importantly, the fundamental value is independent of the investment horizon.

Equation (1) governs the relation between individual forecasts and market clearing prices that we use in our LtF laboratory experiment. ${ }^{11}$ Note that in period

\footnotetext{
${ }^{11}$ As all investors have the same investment horizon, there is no structural dependence between subsequent periods for $H>1$. For example, when $H=2$, price expectations for the odd periods
} 
$t$, subjects have to predict the price for time $t+H$ on the basis of information up to time $t-1$, since $p_{t}$ is not in their information set yet. ${ }^{12}$

The price generating mechanism (1) defines the current market price $p_{t}$ as a weighted average of the fundamental value and average expectations for the price in period $t+H$. This creates positive expectations feedback: an increase in average expectations of the future price increases the demand for the asset and, through market clearing, leads to an instantaneous increase in the current market price. The strength of this feedback is given by the discount factor $1 / R^{H}$ in (1) which diminishes with the investment horizon, with $R^{H}$ reflecting the opportunity cost of investing in the risky asset. As a consequence, an expected price increase will have a smaller effect on the market clearing price, if it lies in the more distant future..$^{13}$

A potential issue for $\mathrm{LtF}$ experiments based on the pricing equation (1) is that extreme 'outlier' forecasts have a substantial effect on the realized price dynamics. One way around this problem would be to let the realized price be a function of the median, instead of the average, forecast, as in Arifovic and Petersen (2017). Another possibility would be to exclude forecasts that deviate too much from the last price when determining the average forecast, as in Kopányi-Peuker and Weber (2019). Whereas both procedures mitigate the effect of extreme predictions, they are not consistent with the underlying asset pricing model. For this reason we use the standard LtF setup in our experiment.

\subsection{Treatments}

In our experiment, participants have to forecast asset prices for about 50 consecutive periods. The instructions (see Appendix B) specify the participant's role as a "financial forecaster" for a large pension fund. It is explained that the participant's task is to give point forecasts of the future asset price, and that based on those forecasts, the pension fund the participant advises will make trading decisions. Following the standard practice of LtF experiments, the instructions do not specify the exact pricing equation. However, they highlight qualitative features of

determine prices in the odd periods, and price expectations for even periods determine prices in even periods. However, there could be a behavioral dependence: expectations could be informed by past prices from both odd and even periods.

${ }^{12}$ For this reason, experiments with $H=1$ are referred as "two-periods ahead" LtF experiments in the literature. To avoid confusion we will not use this terminology.

${ }^{13}$ Mean-variance optimization underlying our theoretical model results in a constant discount factor per period, inversely related to the gross return of the risk-free asset. The discount factor gets smaller with a longer horizon, reflecting that investors betting on growing prices of the risky asset require a larger expected price increase to hold the asset for a longer time. 


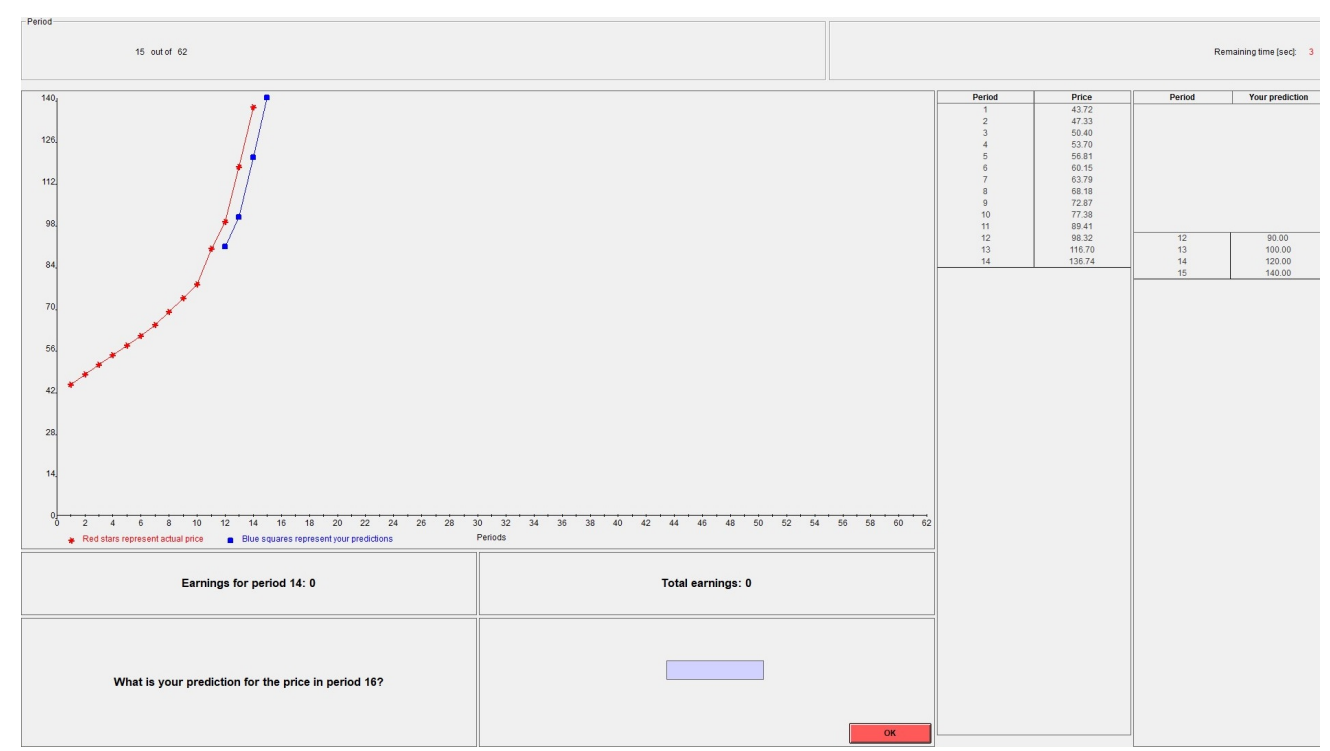

Figure 1: An example of the experimental screen.

the market, e.g., that a higher price forecast leads to a larger demand for the asset by the fund, that there are several funds affecting the total demand (the number of funds is unknown to the participants), and that the realized price follows from the equilibrium between aggregate demand and fixed supply. The numerical values of the interest rate $r$ and the mean dividend $\bar{y}$ are provided to the participants. We choose values in such a way that the fundamental price is 60 in all treatments. The instructions carefully explain the timing of the forecasting task, i.e., for how many periods ahead the price forecast is made, and how forecasting accuracy is determined.

During the experiment, the information at the disposal of a participant consists of all past realized prices and own past predictions shown in the computer screen, see Fig. 1. This information is presented in both graph and table format. The last period earnings and cumulative earnings are also shown in the screen. In each decision period, participants should type their forecast in the box in the lower part of the screen and submit it by pressing the 'OK' button. ${ }^{14}$ The timer in the upper part of the screen suggests participants to submit their forecast within 30 seconds, but this is not a binding restriction.

Participants are rewarded for their forecasting accuracy under the following

\footnotetext{
${ }^{14}$ No restrictions are given to the participants about the prices they can submit. However, to be consistent with earlier LtF experiments, only numbers between 0 and 1000 with up to two decimal places are accepted. A participant will only learn about these restrictions after trying to submit a prediction that is not acceptable with a prompt indicating the bounds and asking to submit another prediction. This rarely happens in our experiment.
} 


\begin{tabular}{|c|c|c|c|c|c|c|c|}
\hline Treatment & $\begin{array}{l}\text { Initial } \\
\text { price }\end{array}$ & $\begin{array}{c}\text { Horizon } \\
H\end{array}$ & $\begin{array}{c}\text { Interest } \\
r\end{array}$ & $\begin{array}{c}\text { Dividend } \\
\bar{y}\end{array}$ & $\begin{array}{l}\text { Feedback } \\
1 /(1+r)^{H}\end{array}$ & $\begin{array}{c}\text { Paid } \\
\text { periods }\end{array}$ & $\begin{array}{l}\text { Number of } \\
\text { groups }\end{array}$ \\
\hline ConH1 & & 1 & $5 \%$ & 3 & 0.95 & $12-61$ & 3 \\
\hline ConH2 & Converging & 2 & $5 \%$ & 3 & 0.91 & $13-62$ & 4 \\
\hline ConH3 & & 3 & $5 \%$ & 3 & 0.86 & $14-63$ & 3 \\
\hline OscH1 & & 1 & $5 \%$ & 3 & 0.95 & $12-61$ & 8 \\
\hline OscH2 & Acoillatin & 2 & $5 \%$ & 3 & 0.91 & $13-62$ & 5 \\
\hline OscH3 & Oscillating & 3 & $5 \%$ & 3 & 0.86 & $14-63$ & 6 \\
\hline OscH3SF & & 3 & $1.6 \%$ & 0.96 & 0.95 & $14-63$ & 6 \\
\hline
\end{tabular}

Table 1: Information on experimental design.

scoring rule widely used in LtF experiments:

$$
e_{i, t}=\max \left\{1300-\frac{1300}{49}\left(p_{t}-p_{i, t}^{e}\right)^{2}, 0\right\},
$$

where $e_{i, t}$ are the points earned by participant $i$ in period $t$ and $p_{i, t}^{e}$ is the participant's point prediction for price $p_{t}$. Rule (2) is decreasing in the quadratic forecasting error, providing incentives to make accurate predictions, and is truncated at zero to avoid that participants suffer losses. Points accumulated during 50 periods (as specified below) are converted to Australian dollars (AUD), with the exchange rate of 0.5 AUD for 1300 points, and are paid to the participants on top of a show-up fee.

Our experiment features seven treatments summarized in Table 1. For each treatment, we have $N=6, p^{f}=60$ and $\varepsilon_{t} \sim N(0,0.25)$. The same realization of shocks $\varepsilon_{t}$ is used in every group of each treatment. The treatments differ along three dimensions. First, we use two different initial price histories as initial conditions for the experiment, to study the effect of previous price developments on the ensuing price dynamics in a positive expectations feedback environment. For the two initial price histories, we take the first 10 prices in two groups from the standard LtF experiment in Hommes et al. (2005). The left panels of Fig. 3 below start with 10 prices observed in group 6 of the Hommes et al. (2005), and the right panels start with 10 prices observed in group 7 of the same experiment. Both price histories are hill-shaped and deviate from the fundamental price, which is 60 in both our and the Hommes et al. (2005) experiment. However, the deviations of the first price history (all 10 prices are between 56.0 and 60.0) are much smaller than those of the second price history where all prices are between 44.8 and 67.1. From now on we will refer to the first price history as "Converging" and to the second price history as "Oscillating". ${ }^{15}$ Note that, given the initial price history

\footnotetext{
${ }^{15}$ The two price histories are qualitatively relatively similar, with prices first increasing up to, or larger than the fundamental value, and then decreasing again. Alternatively, we could have chosen price histories that are farther apart (e.g., one where prices slowly approach the
} 
of 10 periods, the first price that is determined endogenously in the experiment is the price in period $t=11$.

The second, and most important, variation in treatments is the investment horizon $H$ that affects pricing equation (1). All participants in the same treatment have the same investment horizon, which is either $H=1, H=2$, or $H=3$. For treatments with $H=1$, participants start the experiment by predicting the price for period 12. These forecasts determine, through equation (1), price $p_{11}$. After learning this price, participants predict the price for period 13, which determines $p_{12}$, and so on. The final forecast is for period 62 , and determines price $p_{61}$. The forecasting accuracy of the participants' predictions can only be evaluated for periods 12 up to 61, and participants will, therefore, be rewarded for their forecasts for these 50 periods. Similarly, for treatments with $H=2$ the first prediction, which determines $p_{11}$, is for the price in period 13 and the final prediction is for the price in period 64 and determines $p_{62}$. Therefore, in treatments with $H=2$ participants will be rewarded for their 50 predictions for periods $13-62$. Finally, for treatments with $H=3$ the first prediction, determining $p_{11}$, is for period 14 and the final prediction, determining $p_{63}$, is for period 66 and the participants in these treatments will be rewarded for their 50 predictions for periods $14-63$. That is, although participants in, e.g., treatments with $H=3$ submit predictions for periods 64, 65 and 66, these predictions are not incentivized.

By having two price histories and three investment horizons, we have a $2 \times 3$ between-subjects design. In each of these six treatments we set $r=0.05$ and $\bar{y}=3$, leading to the fundamental price $p^{f}=60$. We also run one more treatment with the oscillatory initial price history and investment horizon $H=3$, but with a lower interest rate, $r=0.016$ and a mean dividend of $\bar{y}=0.96$. This combination of lower interest rate and lower mean dividend gives rise to the same fundamental value, $p^{f}=60$, as in the other treatments. However, the feedback strength, $1 / R^{H}$, for this new treatment (with $H=3$ ) is now the same as that for the original treatment with $H=1$. We refer to this treatment as the OscH3SF treatment, where SF stands for 'strong feedback'.

fundamental value from below versus one where prices are monotonically increasing and go far beyond the fundamental value in the first 10 periods). To focus on the effect of even small differences in initial conditions, we did not want to make the differences between the two price histories too large. 


\subsection{Hypotheses}

For $H=1$, the pricing equation (1) corresponds to the price generating mechanism used in earlier LtF experiments (see, e.g., Hommes et al., 2005, 2008, 2020). The following results from these experiments are remarkably robust, although there are minor differences in the experimental design. ${ }^{16}$ Price dynamics often do not converge to the fundamental value within 50 periods, and instead are characterized by the emergence of large bubbles and crashes, with prices regularly approaching the upper bound of 1000, exceeding the fundamental value by a factor of 16 . Moreover, although participants cannot observe each others' forecasts, individual forecasts of participants in the same group are highly coordinated. These results have been attributed to the positive expectations feedback of the price generating mechanism. For instance, for a standard choice of $R=1.05$, the market price in (1) will be close to the average expected price, even when this average deviates from the fundamental value. Participants that submit forecasts that are close to the average forecast in their group will perform relatively well. This feature promotes coordination of expectations and, as a consequence, forecast errors are typically strongly correlated across participants. Moreover, as soon as price deviates from the fundamental value, participants tend to coordinate on a so-called trend-following heuristic

$$
p_{i, t+1}^{e}=p_{t-1}+\theta\left(p_{t-1}-p_{t-2}\right)
$$

with positive $\theta$. This forecasting rule extrapolates the most recent trend in prices into the future. For large enough $\theta$, the use of such a rule is consistent with the endogenous emergence of bubbles. ${ }^{17}$ Indeed, such rules have been frequently observed in LtF experiments, for example, in (Hommes, 2005).

Our experiment aims at understanding the effect of providing a price history and increasing the investment horizon on the emergence of asset price bubbles. To the best of our knowledge, in all LtF experiments, except Hennequin (2019), participants start the experiment without any prior information about prices. ${ }^{18}$ Given the path dependency observed in these earlier experiments, i.e., the finding that the price dynamics in the initial periods can help explain the price dynamics

\footnotetext{
${ }^{16}$ For example, in Hommes et al. (2005) stabilizing 'robot' traders are added to most groups. The number of participants per group varies across experiments from $N=6$ in Hommes et al. $(2005,2008)$, to around 100 in some of the groups in Hommes et al. (2020).

${ }^{17}$ See the discussion of Fig. 2 below.

${ }^{18}$ In most LtF experiments, participants are only told that the first two prices are "likely" to lie between 0 and 100. Even when the values of $\bar{y}$ and $r$ are given explicitly, and so the fundamental value $p^{f}=\bar{y} / r$ can, in principle, be computed, very few participants appear to use this information.
} 
in the remaining periods of the experiment (see Anufriev and Hommes, 2012a), we conjecture that the difference in price histories will affect price dynamics in our experiment, as formulated in our first hypothesis.

Hypothesis 1. Price volatility will be higher in groups with an oscillating initial price history than in groups with a converging initial price history.

To test this hypothesis, we will compare price volatility between treatments with the same horizons (and interest rate) but different price histories. That is, we will compare treatments ConH1 and OscH1, treatments ConH2 and OscH2, and treatments ConH3 and OscH3.

Our remaining hypotheses are concerned with the effect of the investment horizon on aggregate price behavior and individual predictions. When comparing the pricing equation (1) for different values of $H$, two effects stand out. First, as explained above, the feedback strength $\left(1 / R^{H}\right)$ decreases with $H$. This effect is stabilizing for the price dynamics, because with longer horizons any deviation of the average prediction from the fundamental value will result in a smaller price deviation (see Sonnemans and Tuinstra, 2010 for the effect of feedback strength on price dynamics). Second, participants have to predict further into the future. In particular, if they believe that prices will increase between two subsequent periods, they have to extrapolate this price increase accordingly over their investment horizon. To be specific, assume that all participants believe that prices between two subsequent periods evolve as in (3) with $\theta \geq 0$. By iterating this equation forward, we obtain

$$
p_{i, t+H}^{e}=p_{t-1}+\theta\left(1+\theta+\cdots+\theta^{H}\right)\left(p_{t-1}-p_{t-2}\right)
$$

for a participant with investment horizon $H$. As one would expect, an increase in $H$ will lead to an increase in the expected price change. Hence, the trendfollowing heuristic will amplify price trends stronger, when the horizon is longer. Thus, this effect is destabilizing for the price dynamics. On the other hand, it assumes a consistent use of the trend-following heuristic over time, as in (4), which is computationally more demanding for longer horizons.

It depends on the values of $\theta, R$ and $H$, how the destabilizing effect of a further extrapolation compares to the stabilizing effect of a lower feedback strength. To illustrate this dependence, assume that all participants use trend-following heuristic (4) and that there are no supply shocks in in the market-clearing equation (1). Then price dynamics in deviations from the fundamental level $x_{t}=p_{t}-p^{f}$ are 


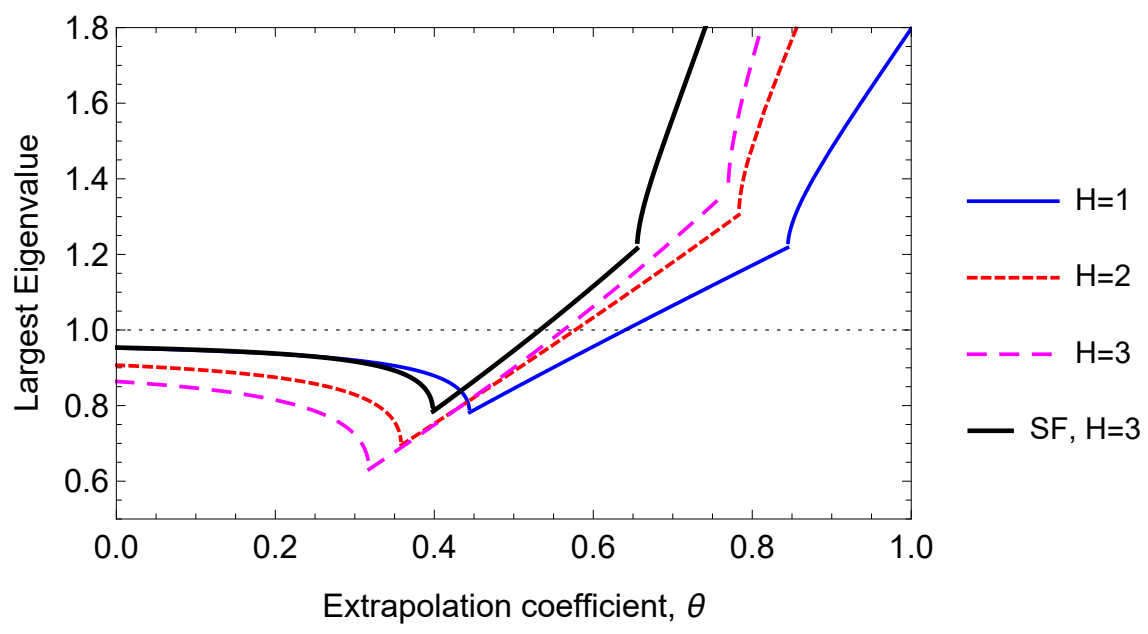

Figure 2: The largest eigenvalue for trend-following behavior in system (5).

given by

$$
x_{t}=\frac{1}{R^{H}}\left(x_{t-1}+\theta\left(1+\theta+\cdots+\theta^{H}\right)\left(x_{t-1}-x_{t-2}\right)\right) .
$$

This is a second-order linear difference equation whose steady state, $x=0$, corresponds to the fundamental value. The speed of convergence to this steady state (or divergence from it) depends on the largest eigenvalue in modulus of this system. Fig. 2 depicts this largest eigenvalue as a function of the extrapolation coefficient $\theta$ for all combinations of $H$ and $R$ considered in this paper. The horizontal black line corresponds to the threshold value 1 . Price dynamics is stable if the largest eigenvalue is below this threshold and unstable otherwise. Generally, the higher the largest eigenvalue is, the faster the price diverges (or the slower it converges).

Three curves labeled ' $\mathrm{H}=1$ ', ' $\mathrm{H}=2$ ' and ' $\mathrm{H}=3$ ' show the largest eigenvalue for the corresponding horizon, when $R=1.05$. We observe that for small $\theta$ an increase in $H$ stabilizes the system, and for large $\theta$ such an increase destabilizes it. ${ }^{19}$ The effect of an increase in the investment horizon is, therefore, a priori ambiguous, even if participants form expectations consistently across different investment horizons. Estimations of the forecasting rules reported in Hommes et al. (2005) and supported by later LtF experiments with $H=1$ and $R=1.05$ show that the value of $\theta$ in the trend-following heuristic (3) is typically above 0.4 and can be as large as 1. Although, it does not resolve all ambiguity, this provides the basis for the following hypothesis.

Hypothesis 2. An increase in the investment horizon $H$ leads to an increase in

\footnotetext{
${ }^{19}$ All three curves intersect when $\theta=\theta^{c} \approx 0.44$, when the horizon effect reverses. The fundamental value is stable for $\theta<0.64$ if $H=1$, for $\theta<0.58$ if $H=2$, and for $\theta<0.56$ if $H=3$. The fundamental value is stable for $\theta<0.53$ if $H=3$ and the feedback is strong as in the OscH3SF treatment. All threshold values are computed numerically.
} 
price volatility.

To test this hypothesis, we will compare price dynamics across treatments ConH1, ConH2 and ConH3, and across treatments OscH1, OscH2, and OscH3.

As discussed, the ambiguity of the horizon effect arises because the change of the horizon affects the feedback strength. Treatment OscH3SF is designed to remedy this effect: it features the same feedback strength as treatment OscH1, but the investment horizon is longer. The black solid line in Fig. 2 shows the largest eigenvalue for treatment OscH3SF, when $R=1.016$ and $H=3$. For small $\theta$, the stability is very similar to treatment OscH1, but for large $\theta$ the system is more unstable than in other cases. Therefore, provided that trend-extrapolating participants take the investment horizon into account when forecasting future prices, we expect to see less stable price dynamics in treatment OscH3SF than in treatment OscH1. In addition, price dynamics in treatment OscH3SF should be less stable than in treatment $\mathbf{O s c H 3}$ as well, because feedback strength is higher in OscH3SF than in OscH3, but the investment horizon is the same.

Hypothesis 3. Prices in treatment $\mathbf{O s c H 3 S F}$ are more volatile than prices in treatments $\mathbf{O s c H 1}$ and $\mathbf{O s c H 3}$.

If we do not find a significant difference between treatments OscH3SF and OscH1, this may be because participants do not take into account the longer investment horizon when extrapolating in the former treatment. In fact, both Hypothesis 2 and Hypothesis 3 are based upon the behavioral assumption that participants extrapolate past prices stronger in their predictions when they face a longer investment horizon. We use this observation to formulate the following hypothesis.

Hypothesis 4. Forecasts of participants in treatments with longer investment horizons are characterized by a stronger degree of trend extrapolation.

Earlier LtF asset pricing experiments are characterized by strong coordination of expectations on a common, trend extrapolating, prediction strategy. Strong coordination further contributes to the endogenous emergence of bubbles. Because in our experiment participants have to predict further ahead in treatments with $H>1$, forming predictions there might be cognitively or computationally more demanding. This may lead to a larger heterogeneity across individual forecasts, impeding coordination and the emergence of bubbles. This observation gives rise to our final hypothesis. 
Hypothesis 5. Coordination of expectations in treatments with longer investment horizons will be lower than in the treatments with shorter investment horizons.

We will test this last hypothesis by comparing the dispersion of forecasts across treatments ConH1, ConH2 and ConH3, and across treatments OscH1, OscH2, and OscH3.

\section{Price dynamics, investment horizons and price histories: Experimental results}

We start the discussion of our experimental results with analyzing the impact of the initial price history and the length of the investment horizon on market price volatility in Section 3.1. To understand the findings presented there, we subsequently turn our attention to forecasting behavior in Section 3.2, and discuss the effect of the investment horizon on the coordination of expectations and on participants' tendency to extrapolate trends in prices. For our analyses in Sections 3.1 and 3.2 we restrict attention to the periods for which participants have submitted a forecast, and for which a market price is available. ${ }^{20}$ This gives 50 observations on prices and predictions for each group. ${ }^{21}$

\subsection{Aggregate market dynamics}

We have 35 groups in our experiment in total, divided over seven treatments, see Table 1. Fig. 3 shows the evolution of prices for each of these groups, organized by

\footnotetext{
${ }^{20}$ These are the same periods for which participants are rewarded, i.e., periods $12-61$, periods $13-62$ and periods $14-63$, for treatments with $H=1, H=2$ and $H=3$, respectively. See Table 1.

${ }^{21}$ As discussed in Section 2.1, the LtF experiments are vulnerable to forecasts or behaviors that are seemingly unrelated to the price dynamics. Both types of such outliers were present in our experiment, which forced us to exclude some data from the analysis. First, nine of the last ten forecasts of participant 5 in group 1 of treatment $\mathbf{O s c H 3 S F}$ are equal to either 0, 999 or 1000. These extreme predictions have a large impact on the realized market price in periods $54-63$ in that group. We excluded those periods in that group from the analysis. Second, we excluded two groups from the analysis altogether. In a group from treatment ConH1, all predictions of one participant are much lower (5.0 on average and never higher than 15.4) than both the initial prices (all ten of which are at least 56.0) or the realized prices (which are 23.8 on average). In a group from treatment $\mathbf{O s c H 2}$, the predictions of one participant start with 60.59 for period 13, then monotonically decrease to 2.15 for period 32 , after which they monotonically increase up to 102.85 for period 64 . In both cases, these peculiar forecasting rules have an important effect on the entire price dynamics. Our results are qualitatively robust with respect to inclusion of outliers (these results are available from the authors upon request).
} 

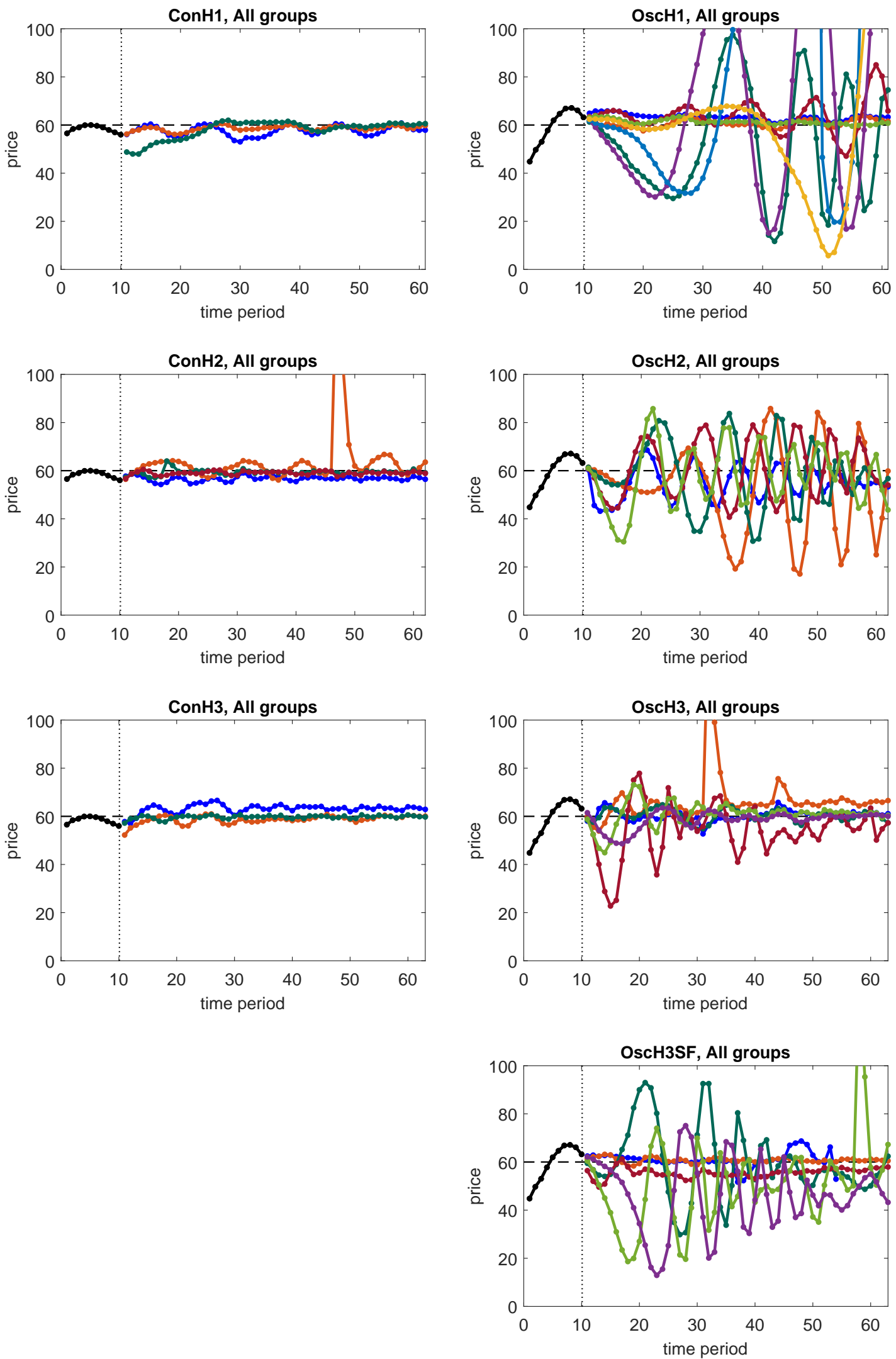

Figure 3: Price dynamics in all experimental treatments. The initial price history for periods 1-10 is shown in black. Experimental price dynamics in different groups is shown with different colours. The constant fundamental price of 60 is shown by the dashed line. 


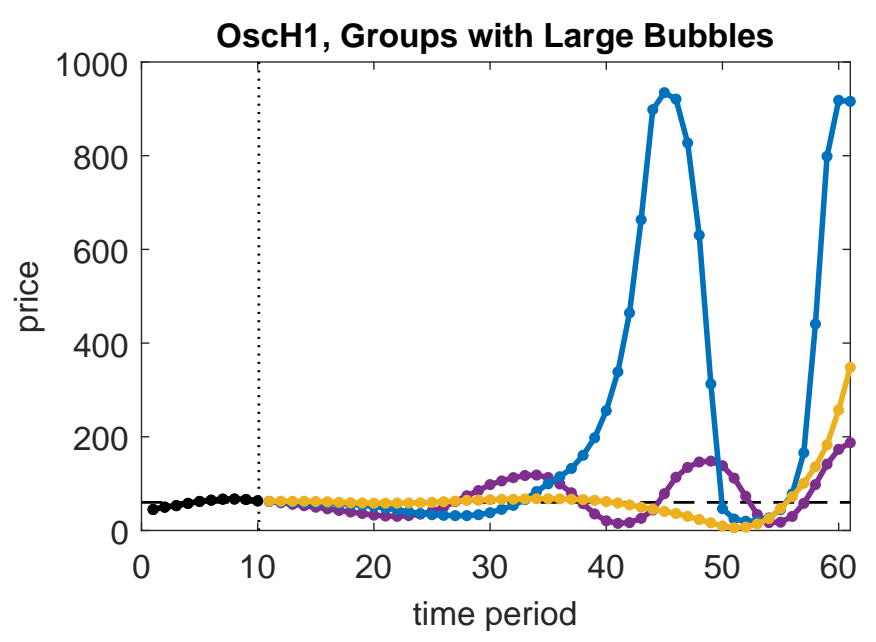

Figure 4: Price dynamics in groups 6, 7 and 8 of the OscH1 treatment.

treatment. $^{22}$ The left panels of Fig. 3 present market prices for the groups in the ConH1, ConH2 and ConH3 treatments, and the right panels present market prices for the groups in the OscH1, OscH2, OscH3 and OscH3SF treatments, respectively. The first ten periods in each panel show the initial price history (in black). This initial history is the same for all groups in the same treatment but differs between the Con and Osc treatments, as explained in Section 2.2. To facilitate the comparison, all panels in Fig. 3 have the same vertical scaling, from 0 to 100 . However, in three out of the 35 groups prices systematically go above 100. These three groups are all from treatment OscH1, and prices in these groups (groups 6, 7 and 8) are shown separately in Fig. 4 with a larger vertical scale. ${ }^{23}$

We make several observations based on Figs. 3 and 4. First, there is an apparent effect of the initial price history on market price dynamics. Price oscillations in all 10 groups that start with the converging initial price history are limited, whereas more than half of the groups that start with the oscillating initial price history lead to substantial and persistent oscillations. Second, the treatments with $H=1$ can be compared to earlier LtF experiments. As discussed above, these experiments - where no initial price history was given to participants - often lead to large bubbles in asset prices with prices rising to more than 10 times the funda-

\footnotetext{
${ }^{22}$ See Appendix D for the evolution of prices and predictions for each group separately.

${ }^{23}$ There are two other instances where the price is above 100 for only one period. These are period 32 in group 2 of treatment OscH3 and period 58 in group 5 of treatment OscH3SF, when the price suddenly jumps to 145 and 134, respectively, and drops below 100 again in the subsequent period. In both cases, this is due to a sudden extreme prediction by one of the participants. The reason might be an accidental typo by that participant. For example, in the first case a participant predicts 647 instead of 64.7 , where the latter would be very much in line with the last observed price and the participant's preceding forecasts.
} 
mental value. ${ }^{24}$ In our experiment, such a large bubble only emerges in one out of the eight groups (group 7) in treatment OscH1 and in none of the three groups in ConH1. This observation suggests that, compared to giving no price history at all, the oscillating initial price history also tends to reduce the incidence of large bubbles substantially. That may happen because the last couple of periods of this oscillating initial price history prices decrease again. This effect alone is sufficient to inhibit the emergence of large bubbles, although the oscilating initial prices history does tend to increase price volatility.

The effect of the investment horizon on price volatility is more difficult to distill from Fig. 3. Price dynamics in all groups from the Con treatments are relatively stable with no visible effect of the investment horizon on price volatility (which is low for all groups in these treatments). For the Osc treatments, the general picture is somewhat blurred by the heterogeneity between outcomes in the same treatment. For example, three of the groups in treatment $\mathbf{O s c H 1}$ are characterized by relatively stable price dynamics. In contrast, the other five groups either show persistent oscillations from the start or feature such oscillations in the second half of the experiment. Similarly, one of the six groups in treatment OscH3 and three of the six groups in treatment OscH3SF show persistent oscillations, with price dynamics in the other groups in those treatments relatively stable. Only in treatment OscH2 behavior across the different groups is relatively homogeneous, with persistent price fluctuations in all five groups of that treatment.

Notwithstanding this heterogeneity, the Osc treatments do not seem to provide much evidence in support of a positive effect of the investment horizon on price volatility. Although the fraction of groups that are characterized by persistent fluctuations goes up from 5 out of 8 to 5 out of 5 , when going from treatment OscH1 to treatment OscH2, it falls to 1 out of 6 in treatment OscH3. Also, the maximal amplitude of the price oscillations is different between treatments. In three groups in treatment OscH1, illustrated in Fig. 4, prices eventually grow much larger than 100, whereas prices in treatments OscH2, OscH3 and OscH3SF consistently stay below 100, even in groups that exhibit persistent oscillations. All this points towards the conclusion that increasing the time horizon impedes the emergence of large bubbles. Finally, when comparing treatment OscH3SF which compensates for the decrease in feedback strength - with treatment OscH1, the former does not appear to lead to higher price volatility, with only 3 out of 6 groups showing persistent fluctuations; these fluctuations are much smaller than the largest fluctuations in treatment OscH1. Therefore, an increase in the invest-

\footnotetext{
${ }^{24}$ For example, this is the case for five of the six groups in Hommes et al. (2008) whose design, apart from the initial price history, is essentially equivalent to our treatments with $H=1$.
} 

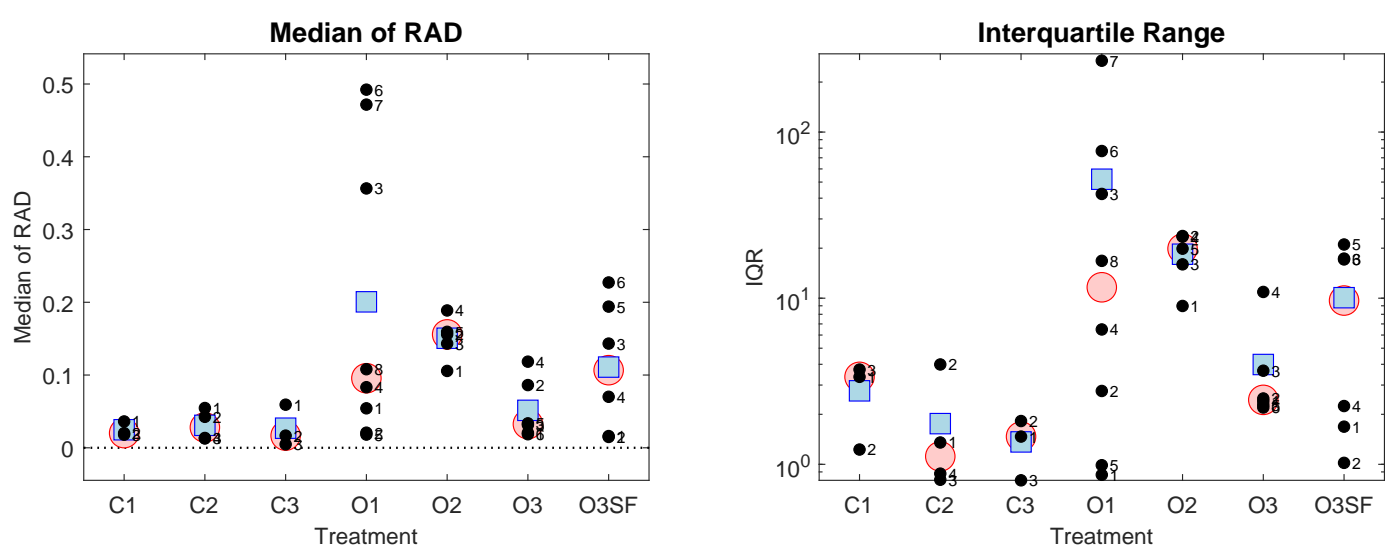

Figure 5: Left: Level of mispricing measured as the median of the relative absolute deviation. Right: Level of volatility measured as the Interquartile Range (log scale). For both panels, the data are organized by treatments, where the statistics for individual groups (black dots), the median for the treatment (red circle), and the average for the treatment (blue square) are shown.

ment horizon seems more likely to decrease price volatility, rather than to increase it. $^{25}$

To corroborate these impressions, we consider two measures that quantify price volatility. The first measure is the median $R A D$, i.e., the median (over all incentivized periods in a group) of the relative absolute deviation of price from the fundamental price, $\left|p_{t}-p^{f}\right| / p^{f}$. The RAD is one of the measures proposed by Stöckl et al. (2010) to study bubbles in asset market experiments. ${ }^{26}$ Our second measure is the interquartile range (IQR), i.e., the length of the interval that contains the middle $50 \%$ of the prices from the given group. Fig. 5 depicts both measures for all 35 groups in the experiment, as well as the mean (blue squares) and median (red circles) of these measures for every treatment. The numeric values of these and other descriptive statistics can be found in Table 2 in Appendix C.1.

The quantitative measures depicted in Fig. 5 are consistent with our earlier observations. All groups from the Con treatments have low values of both measures. In contrast, a substantial number of groups from the Osc treatments have

\footnotetext{
${ }^{25}$ The following observation further supports this conclusion. Bao and Hommes (2019) vary feedback strengths in an LtF experiment with $H=1$. Their treatment $\mathrm{L}$ has a feedback strength 0.86, coinciding with the feedback strength in our treatment OscH3. However, where we only find persistent oscillations in 1 out of 6 groups in treatment OscH3, Bao and Hommes (2019) find persistent oscillations in all 5 groups in their treatment L. Note that this difference may also partly be attributed to the absence of an initial price history in Bao and Hommes (2019).

${ }^{26}$ Instead of looking at the mean value of the relative absolute deviations, as in Kirchler et al. (2012), for example, we look at the median value. This limits the effect of outliers caused by extreme predictions.
} 
much higher values of these measures (note the log-scale of the right panel for the IQR). At the same time, there are some groups from these four treatments for which the measures are comparable to the values from the Con treatments. We perform pairwise tests of similarity of both measures between the treatments. The p-values of three non-parametric tests (the Kolmogorov-Smirnov, FischerPitman and Mann-Whitney-Wilcoxon tests) are reported in Appendix C.2 and Appendix C.3 for the median RAD and IQR, respectively. All tests show that there is a significant difference, at least at the $5 \%$ level, for both measures, between treatment $\mathbf{O s c H 2}$ and treatment ConH2. The other relevant comparisons (i.e., keeping the same horizon) are not as strong but point in the same direction. For the comparison of treatments ConH1 and OscH1, the difference in median RAD is significant for two tests at the $10 \%$ level, but the difference in IQR is not statistically significant. For the comparison of treatments ConH3 and OscH3, the difference in median RAD is not significant, but for two of the three tests the difference in IQR is significant at the $5 \%$ level. The heterogeneity in outcomes in treatment OscH1 and, to a lesser extent, in treatment OscH3, which can be seen in Fig. 5, may explain the lack of strongly significant differences in outcomes. This heterogeneity is small in treatment OscH2, which is precisely the treatment for which the most convincing results are obtained.

Based upon our discussion and tests, we conclude that we cannot reject Hypothesis 1. Instead, we find the support for the following result.

Result 1. The initial price history plays an important role in subsequent price dynamics. Price volatility is higher for treatments with the oscillating initial price history than for treatments with the converging initial price history.

Fig. 5 confirms another observation. There seems to be only very little effect of an increase in the investment horizon in the Con treatments, and there is no clear support for an increase in volatility with the investment horizon in the Osc treatments. In fact, for treatments OscH1, OscH2 and OscH3 the average values of both the mean RAD and the IQR are lower for longer horizons, and the same holds when comparing treatments OscH1 and OscH3SF. From the statistical tests presented in Appendices C.2 and C.3, we find that the only statistically significant difference (for both measures and all three tests), at the $5 \%$ level is between treatments OscH2 and OscH3, but this shows that volatility is significantly lower in OscH3. In fact, a decrease in volatility when the horizon goes from $H=2$ to $H=3$ is one of the most significant between-treatment comparisons. Also the differences between OscH3SF and treatments OscH1 and OscH3 are not statistically significant. We, therefore, conclude that both Hypotheses 2 and 3 can be rejected. We arrive at our second result. 
Result 2. Price volatility does not increase for longer investment horizons, even after correcting for differences in feedback strength. In fact, it tends to decrease.

We take one more look at prices by characterizing price dynamics in the following way. The simplest linear model that might give rise to oscillations in prices is the following $\operatorname{AR}(2)$ specification

$$
p_{t}=\beta_{0}+\beta_{1} p_{t-1}+\beta_{2} p_{t-2}+\nu_{t} .
$$

Depending on coefficients $\beta_{1}$ and $\beta_{2}$, the dynamics in such a model can be converging, constant or diverging. This dependence is captured by the triangles in $\left(\beta_{1}, \beta_{2}\right)$ coordinates, plotted in Fig. $6 .{ }^{27}$ In particular, the dynamics are converging for the coefficient combinations inside the triangles, diverging for the combinations outside the triangles, and oscillatory for combinations $\left(\beta_{1}, \beta_{2}\right)$ below the parabola.

We fitted the $\operatorname{AR}(2)$ model (6) on the prices for each experimental group. The estimation results can be found in Table 9 in Appendix C.4. The price dynamics in 26 of the 35 markets can be described well by (6), in the sense that the estimated rules pass two specification tests (on autocorrelation and heteroskedasticity) for residuals. We superimposed the estimated values $\left(\hat{\beta}_{1}, \hat{\beta}_{2}\right)$ for each experimental group on the triangles of Fig. 6. Note that almost all estimated pairs lie in the region where the dynamics are characterized by converging oscillations. The only two exceptions are groups 4 and 6 in treatment $\mathbf{O s c H 1}$, where oscillations are diverging. The regularities we identified before are nicely represented by the plots. Estimations in most groups from the Con treatments are relatively far away from the instability boundary $\beta_{2}=-1$. In the Osc treatments, the estimated combinations tend to become more stable (i.e., they lie further away from that boundary) when the investment horizon increases.

\subsection{Trend extrapolation and coordination of expectations}

The results from the previous section suggest that there is a tendency for price volatility to decrease when the investment horizon increases. In fact, large bubbles with prices eventually growing to a level that is a multiple of the fundamental value only appear in our experiment for an investment horizon of $H=1$. As discussed in Section 2.3 the prevalence and size of bubbles in earlier LtF experiments have been attributed to participants in the same group coordinating their forecasts on a trend extrapolating strategy. The absence of large bubbles and the tendency to have

\footnotetext{
${ }^{27}$ The edges of the triangles are given by $\beta_{2}=1-\beta_{1}, \beta_{2}=1+\beta_{1}$ and $\beta_{2}=-1$.
} 

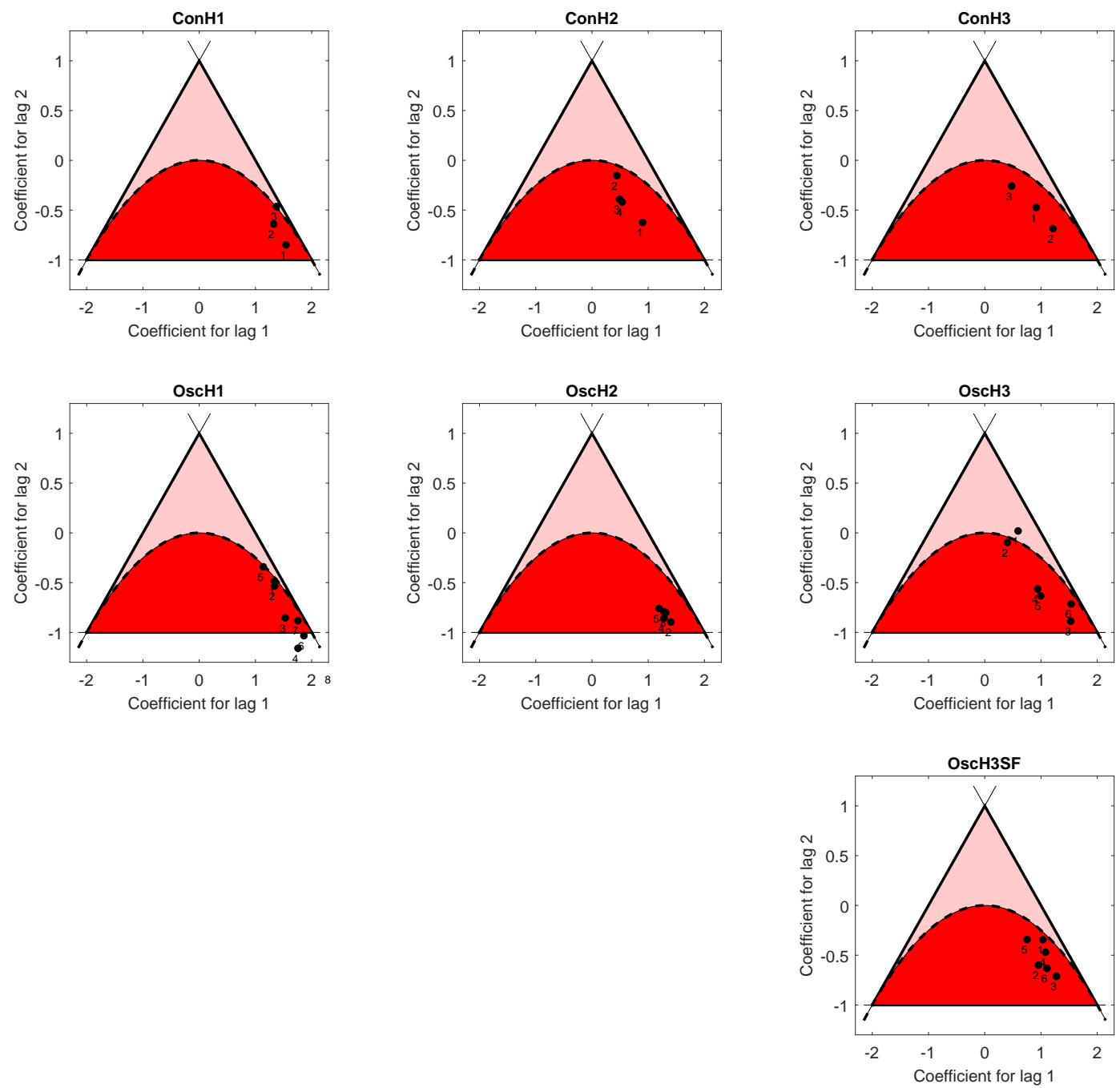

Figure 6: Stability triangles for the $\mathrm{AR}(2)$ model and estimated $\mathrm{AR}(2)$ rules.

fewer groups with persistent asset price fluctuations for longer investment horizons in our experiment might therefore be caused by either a failure of participants to coordinate their expectations, or a failure to coordinate on trend extrapolating strategies, or a combination of both. In this section we will study participants' individual forecasts to better understand how an increase in the investment horizon affects their tendency to coordinate on trend extrapolation strategies. For an illustration of the individual predictions, see Fig. 7, which shows, for one group from each treatment, both the market price (in black) and participants' individual predictions (in color). Plots for all groups can be found in Appendix D.

Recall from Section 2.3 that, if participants believe prices evolve according to $p_{t}=p_{t-1}+\theta\left(p_{t-1}-p_{t-2}\right)$, their predictions should be given by Eq. (4), implying

$$
p_{i, t+H}^{e}-p_{t-1}=\theta\left(1+\theta+\cdots+\theta^{H}\right)\left(p_{t-1}-p_{t-2}\right)
$$



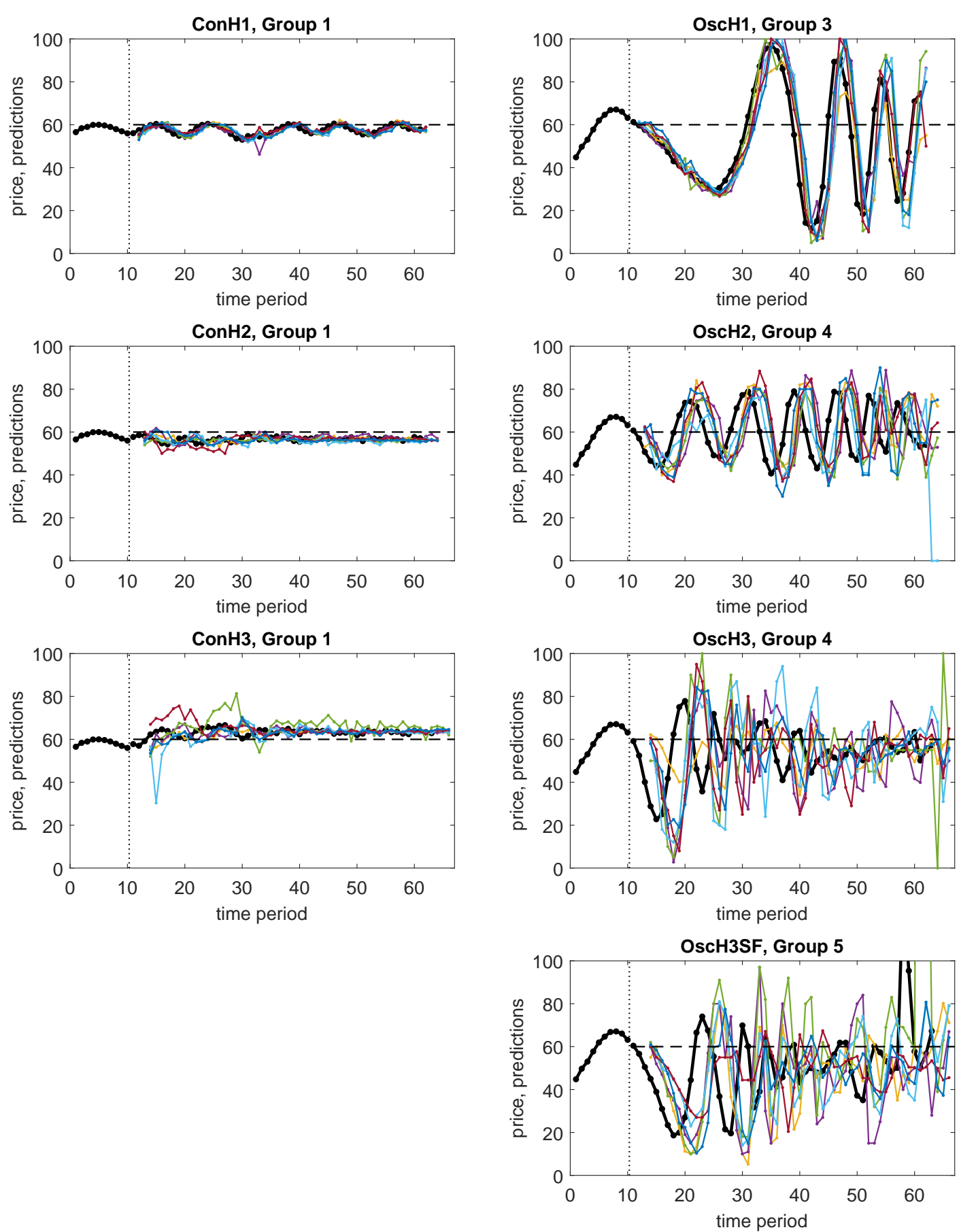

Figure 7: Examples of individual forecast dynamics. Price is shown by the thick black line. The constant fundamental price of 60 is shown by the dashed line.

for investment horizon $H$. Therefore, the effect of the last observed price change, $p_{t-1}-p_{t-2}$, on the expected price increase, $p_{i, t+H}^{e}-p_{t-1}$, should be stronger for longer investment horizons $H$.

To investigate this, Fig. 8 shows scatter plots where, for each of the seven treatments, the averages of participants' expected price changes, $\bar{p}_{t+H}^{e}-p_{t-1}$, are 

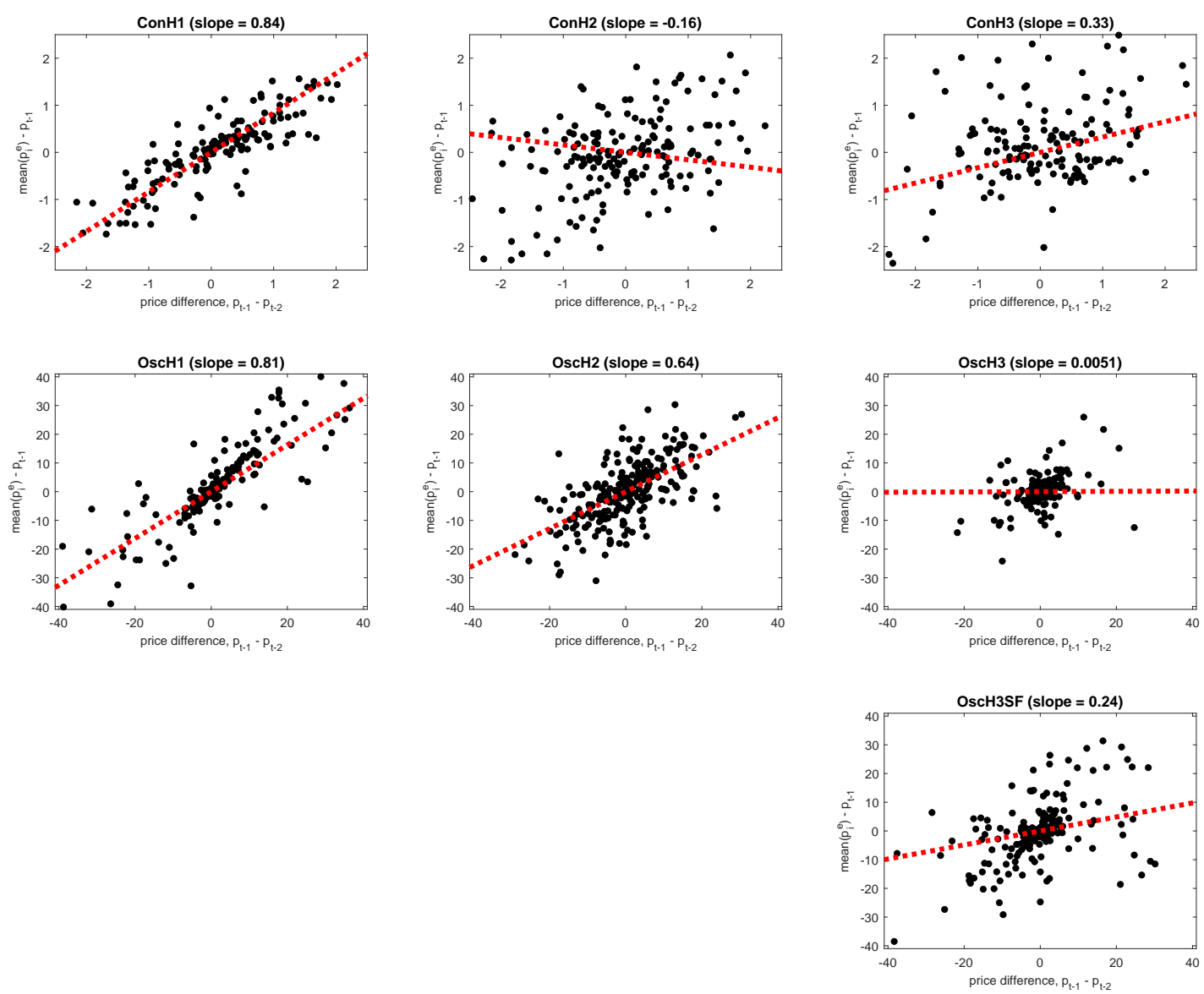

Figure 8: Scatter plots and correlations between $\bar{p}_{i, t+h}^{e}-p_{t-1}$ and the most recent price change, $p_{t-1}-p_{t-2}$.

plotted against the last observed price change, $p_{t-1}-p_{t-2}$. The red line in each panel represents a linear regression line, the slope of which is shown in the title of the panel. According to (7), the slope should increase with the investment horizon, but it actually decreases substantially. ${ }^{28}$ Therefore, participants not only insufficiently account for the investment horizon when extrapolating trends, but their tendency to extrapolate these trends diminishes when the investment horizon increases. We conclude the following.

Result 3. An increase in the investment horizon leads to a substantial decrease in the extent to which trends in past prices are extrapolated.

Result 3, together with the effect of horizons on the feedback strength in the

\footnotetext{
${ }^{28}$ For example, the slope changes from 0.81 in treatment OscH1 to 0.64 in treatment OscH2 to 0.01 in treatment OscH3. The slope for treatment OscH1 is significantly different (at the 10\% level) from the slopes in treatments OscH2, OscH3 and OscH3SF, see Appendix C.5. The slope of 0.81 for $H=1$ is consistent with a value $\tilde{\theta} \approx 0.53$ for the extrapolation coefficient. This would imply slopes $\tilde{\theta}\left(1+\tilde{\theta}+\tilde{\theta}^{2}\right) \approx 0.97$ and $\tilde{\theta}\left(1+\tilde{\theta}+\tilde{\theta}^{2}+\tilde{\theta}^{3}\right) \approx 1.05$ for treatments OscH2 and OscH3, respectively, for forecasting behavior to be consistent between treatments.
} 


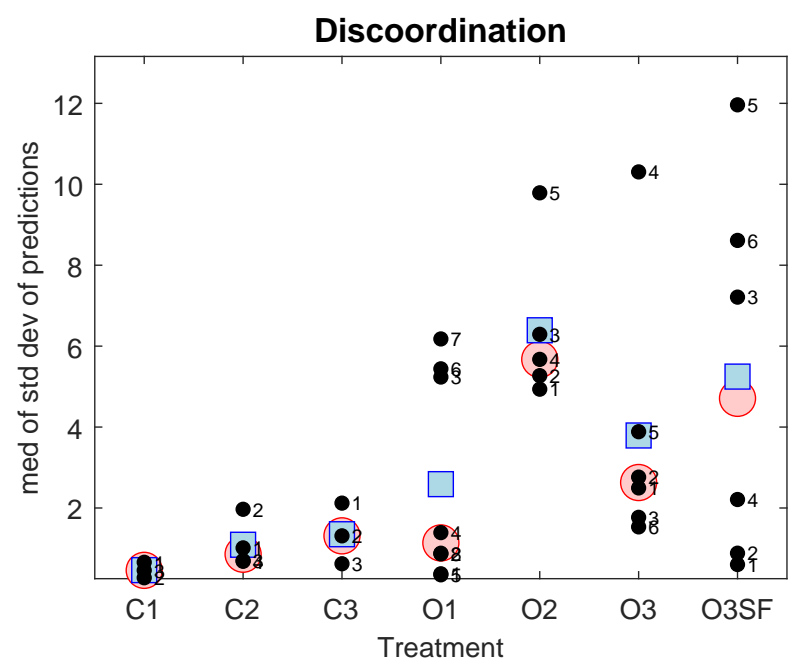

Figure 9: Level of discoordination of predictions in all groups measured as the median of the standard deviation of predictions. For each treatments, the statistics for individual groups (black dots), the median for the treatment (red circle), and the average for the treatment (blue square) are shown.

pricing equation, provides an explanation for why price volatility tends to go down for longer investment horizons. A related, but separate, question is whether participants' ability to coordinate on a common prediction strategy is affected by the investment horizon as well.

From Fig. 7, it appears that predictions within groups are well-coordinated, although there are some differences between treatments. For example, coordination seems to be stronger in group 3 of treatment OscH1 than in group 4 of treatment OscH2 and in group 4 of treatment OscH3. To quantify coordination of expectations, we compute, for each group in our experiment, the standard deviation of the six predictions in each period and take the median of those 50 standard deviations. We will refer to this quantity as the discoordination measure. It is depicted for all groups, and organized by treatment, in Fig. 9. The numeric values can be found in Table 2 from Appendix C.1.

We see substantial heterogeneity in this discoordination measure between groups in the same treatment. Given the heterogeneity in price volatility within treatments, this is hardly surprising: if prices converge to the fundamental value, then typically all forecasts also converge to that value, which reduces the dispersion of the forecasts considerably. However, when restricting attention to the groups with a higher price volatility, there seems to be a tendency for an increase in the investment horizon to adversely affect the level of coordination. Although 

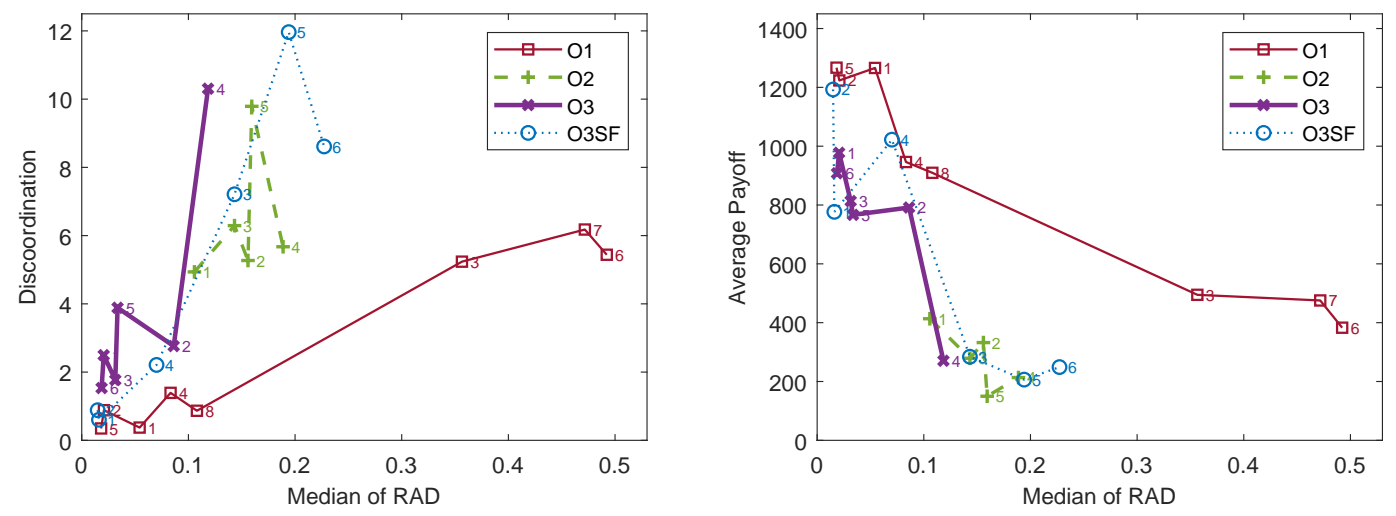

Figure 10: Left: Median of the standard deviation of predictions plotted against median of RAD. Right: Average payoff plotted against median of RAD. The data from the OscH1, OscH2, OscH3 and OscH3SF treatments are used.

one might expect that the dispersion of forecasts is highest in large bubbles, the five groups with the highest dispersion in forecasts are all from treatments with $H=2$ or $H=3$, whereas the largest bubbles emerge in treatment OscH1. The left panel of Fig. 10 explores the relationship between discoordination and price volatility further. It plots, for each group, the median RAD (which measures the price volatility as discussed in Section 3.1) against the discoordination measure. The scatter plot suggests that coordination is easier if the investment horizon is shorter. To see this, note that for groups from different treatments with a similar price volatility, the dispersion of predictions is higher if the investment horizon is longer. Remarkably, the groups with the highest price volatility (groups 3, 6 and 7 from treatment OscH1) are characterized by a smaller dispersion of forecasts than groups with lower price volatility but a longer investment horizon.

Figs. 9 and 10 suggest that the ability of participants to coordinate their forecast on a common prediction strategy decreases when the investment horizon increases. Due to the heterogeneity of outcomes within treatments, the differences between treatments are not always statistically significant (three of the pairwise differences between OscH1, OscH2 and OscH3 are significant at the 5\% level, two are significant at the $10 \%$ level, and the remaining four differences are not statistically significant, see the p-values of the three tests in Appendix C.6). We conclude the following:

Result 4. The extent to which participants are able to coordinate their expectations decreases with the investment horizon.

The fact that coordination of expectations becomes more difficult may be respon- 
sible for the fact that large bubbles do not emerge for longer investment horizons. Note that along such a large bubble, participants are still able to do relatively well if they coordinate their forecasts. As long as a participant's forecasts are close to the average forecast and thereby relatively close to the market price, forecast errors remain reasonably small (although they tend to be smaller when prices are closer to the fundamental value). Participants are, therefore, more willing to 'ride the bubble' if they can coordinate their expectations. If dispersion of the price forecasts is large, at least some participants will make large forecast errors, and low payoffs, along such a bubble. Those participants are then likely to change their forecasting behaviour, and this makes large bubbles unsustainable. The right panel of Fig. 10 supports this explanation for the absence of large bubbles for longer investment horizons. The panel plots the average payoff (the number of earned points, averaged over periods and participants in a group) versus price volatility in that group (represented by the median RAD again). It shows that, for groups that have approximately the same level of price volatility but are from different treatments, the average number of points earned by participants is indeed lower if the investment horizon is longer than one period. Participants in the groups with large bubbles in treatment OscH1 still do better than participants in groups from treatments OscH2, OscH3 and OscH3SF that experience persistent, but much smaller, fluctuations in asset prices.

Large bubbles can develop because of the self-confirming nature of financial markets. If all traders believe the price of an asset will go up, many traders will buy the asset, and the price will indeed go up, because of the increase in demand. For such an expectation-induced asset price bubble to emerge and be sustainable it is, however, necessary that there is a sufficient degree of agreement between traders about the price development of the asset. From the analysis of the individual forecasts in our experiment, we learn that this agreement is difficult to maintain when the investment horizon increases.

\section{Conclusion}

In this paper, we used a Learning to Forecast laboratory experiment to investigate the effect of the investment horizon on asset price dynamics. Although the heterogeneity between groups in the same treatment can be substantial, we are still able to draw some important conclusions. First and foremost, we find that large bubbles and crashes only emerge for an investment horizon of one period. An increase in the investment horizon leads to smaller fluctuations and, on average, 
to a lower price volatility. It is important to note that, apart from how far into the future participants have to predict, there are no other differences in their decision problem for different treatments: participants are only rewarded based on forecasting accuracy and the information they have about the underlying market is independent of the investment horizon. Moreover, the benchmark rational expectation equilibrium is the same for all treatments. The large bubbles that emerge for a short investment horizon seem to be driven by the tendency of participants to coordinate on trend extrapolating prediction strategies that reinforce and amplify initial price fluctuations. If the investment horizon increases, both the extent to which participants extrapolate price trends, and their success in coordinating their predictions decrease, and as a consequence, price volatility goes down.

However, we find that these results may only hold if participants start predicting in a financial market that already features price fluctuations. For an initial price history that is relatively stable the effect of the investment horizon is limited: prices in these markets tend to remain stable for the duration of the experiment.

Our results suggest that policy measures that inhibit the possibility of shorthorizon trading, e.g., by imposing a minimum holding period for the asset, may help in reducing price volatility. However, such measures might also decrease the speed with which private information about the asset is reflected in its price (note that, because information asymmetries are absent, this does not play a role in our experiment). Moreover, from our findings on the effect of initial price histories it follows that the impact of such measures may be mitigated by the historical performance of the market.

There are several avenues for extending our research. First, in our stylized experiment we have only considered investment horizons of up to three periods, and additionally we assumed that all investors active in the same market have the same investment horizon. An obvious extension would be to consider longer horizons (and possibly compensate for the implied reduction in feedback strength, as we did in treatment OscH3SF) or to consider groups composed of participants with different investment horizons (as in Evans et al., 2019). Because both extensions are likely to increase the dispersion of expectations even further (and the first extension likely reduces the level of trend extrapolation) we expect similar (but stronger) effects of differences in the investment horizons. A second, and potentially more interesting, extension would be to consider an experiment with mixed investment horizons, and make the effect that investors with different investment horizons have on the market-clearing price depend on how well participants with that horizon perform. This effect could for example be achieved by letting the weights on individual expectations in pricing equation (1) depend upon the fore- 
cast accuracy of the participants (as in Kopányi et al., 2019). The idea would be that if participants with a shorter time horizon are more accurate in predicting the price and therefore generate more profits for the investors they advise, they may attract more investors. Their impact on the market price therefore could increase, meaning that - even in an environment with mixed horizons - large bubbles may eventually still emerge, making the use of short investment horizons viable. Another relevant extension concerns the initial price history. In treatment OscH1, a relatively small fraction of groups experiences large bubbles, when compared to the results in, e.g., Hommes et al. (2008) and Hommes et al. (2020), which use an experimental design that is, apart from the initial price history, virtually the same as that of treatment OscH1. So, even though the initial price history in treatment OscH1 features oscillations, it still induces more stability than not providing an initial history of prices at all. The question, therefore, is whether a treatment without any initial price history, or with an initial price history that features monotonically increasing prices that already go (far) beyond the fundamental value might still give rise to large bubbles and crashes, even for longer investment horizons.

\section{References}

Allen, F., Morris, S., Shin, H.S., 2006. Beauty contests and iterated expectations in asset markets. The Review of Financial Studies 19, 719-752.

Amromin, G., Sharpe, S.A., 2014. From the horse's mouth: Economic conditions and investor expectations of risk and return. Management Science 60, 845-866.

Anufriev, M., Hommes, C., 2012a. Evolution of market heuristics. Knowledge Engineering Review 27, 255-271.

Anufriev, M., Hommes, C., 2012b. Evolutionary selection of individual expectations and aggregate outcomes in asset pricing experiments. American Economic Journal: Microeconomics 4, 35-64.

Arifovic, J., Petersen, L., 2017. Stabilizing expectations at the zero lower bound: Experimental evidence. Journal of Economic Dynamics \& Control 82, 21-43.

Assenza, T., Heemeijer, P., Hommes, C.H., Massaro, D., 2019. Managing self-organization of expectations through monetary policy: a macro experiment. Journal of Monetary Economics DOI: https://doi.org/10.1016/j.jmoneco.2019.12.005, forthcoming. 
Bao, T., Duffy, J., Hommes, C., 2013. Learning, forecasting and optimizing: An experimental study. European Economic Review 61, 186-204.

Bao, T., Hommes, C., 2019. When speculators meet suppliers: Positive versus negative feedback in experimental housing markets. Journal of Economic Dynamics \& Control 107, 103730.

Bao, T., Hommes, C., Makarewicz, T., 2017. Bubble formation and (in) efficient markets in learning-to-forecast and optimise experiments. The Economic Journal 127, F581-F609.

Bolton, P., Samama, F., 2013. Loyalty-shares: Rewarding long-term investors. Journal of Applied Corporate Finance 25, 86-97.

Bolton, P., Scheinkman, J., Xiong, W., 2006. Executive compensation and shorttermist behaviour in speculative markets. The Review of Economic Studies 73, $577-610$.

Bradbury, M.A., Hens, T., Zeisberger, S., 2015. Improving investment decisions with simulated experience. Review of Finance 19, 1019-1052.

Brock, W.A., Hommes, C.H., 1998. Heterogeneous beliefs and routes to chaos in a simple asset pricing model. Journal of Economic Dynamics \& Control 22, $1235-1274$.

Bushee, B.J., 2001. Do institutional investors prefer near-term earnings over longrun value? Contemporary Accounting Research 18, 207-246.

Campbell, J.Y., Lo, A.W., Lo, A.W., MacKinlay, A.C., 1997. The econometrics of financial markets. Princeton University press.

Cella, C., Ellul, A., Giannetti, M., 2013. Investors' horizons and the amplification of market shocks. The Review of Financial Studies 26, 1607-1648.

Colasante, A., Alfarano, S., Camacho-Cuena, E., Gallegati, M., 2020. Long-run expectations in a learning-to-forecast experiment: a simulation approach. Journal of Evolutionary Economics 30, 75-116.

Cremers, M., Pareek, A., 2015. Short-term trading and stock return anomalies: Momentum, reversal, and share issuance. Review of Finance 19, 1649-1701.

Crouzet, N., Dew-Becker, I., Nathanson, C.G., 2020. On the effects of restricting short-term investment. The Review of Financial Studies 33, 1-43.

De Long, J.B., Shleifer, A., Summers, L.H., Waldmann, R.J., 1990. Noise trader risk in financial markets. Journal of Political Economy 98, 703-738. 
Dow, J., Gorton, G., 1994. Arbitrage chains. The Journal of Finance 49, 819-849.

Evans, G.W., Hommes, C.H., McGough, B., Salle, I., 2019. Are long-horizon expectations (de-) stabilizing? Theory and experiments. Technical Report. Bank of Canada Staff Working Paper.

Fischbacher, U., 2007. z-tree: Zurich toolbox for ready-made economic experiments. Experimental Economics 10, 171-178.

Froot, K.A., Scharfstein, D.S., Stein, J.C., 1992. Herd on the street: Informational inefficiencies in a market with short-term speculation. The Journal of Finance 47, 1461-1484.

Greenwood, R., Shleifer, A., 2014. Expectations of returns and expected returns. The Review of Financial Studies 27, 714-746.

Greiner, B., 2015. Subject pool recruitment procedures: Organizing experiments with ORSEE. Journal of the Economic Science Association 1, 114-125.

Haruvy, E., Lahav, Y., Noussair, C.N., 2007. Traders' expectations in asset markets: experimental evidence. American Economic Review 97, 1901-1920.

Hennequin, M., 2019. Experiences and expectations in asset markets: an experimental study. Working Paper, University of Amsterdam.

Hertwig, R., Barron, G., Weber, E.U., Erev, I., 2004. Decisions from experience and the effect of rare events in risky choice. Psychological Science 15, 534-539.

Hirota, S., Huber, J., Stock, T., Sunder, S., 2015. Investment Horizons and Price Indeterminacy in Financial Markets. Cowles Foundation Discussion Paper.

Hirota, S., Sunder, S., 2007. Price bubbles sans dividend anchors: Evidence from laboratory stock markets. Journal of Economic Dynamics \& Control 31, 18751909.

Hommes, C., 2005. Heterogeneous agent models: two simple examples, in: Nonlinear Dynamical Systems in Economics. Springer, pp. 131-164.

Hommes, C., 2011. The heterogeneous expectations hypothesis: Some evidence from the lab. Journal of Economic Dynamics \& Control 35, 1-24.

Hommes, C., Kopányi-Peuker, A., Sonnemans, J., 2020. Bubbles, crashes and information contagion in large-group asset market experiments. Experimental Economics, forthcoming. 
Hommes, C., Massaro, D., Weber, M., 2019. Monetary policy under behavioral expectations: Theory and experiment. European Economic Review 118, 193212.

Hommes, C., Sonnemans, J., Tuinstra, J., Van de Velden, H., 2005. Coordination of expectations in asset pricing experiments. The Review of Financial Studies 18, 955-980.

Hommes, C., Sonnemans, J., Tuinstra, J., Van de Velden, H., 2007. Learning in cobweb experiments. Macroeconomic Dynamics 11, 8-33.

Hommes, C., Sonnemans, J., Tuinstra, J., Van de Velden, H., 2008. Expectations and bubbles in asset pricing experiments. Journal of Economic Behavior \& Organization 67, 116-133.

Hong, H., Stein, J.C., 1999. A unified theory of underreaction, momentum trading, and overreaction in asset markets. The Journal of Finance 54, 2143-2184.

Kaufmann, C., Weber, M., Haisley, E., 2013. The role of experience sampling and graphical displays on one's investment risk appetite. Management Science 59, $323-340$.

Kirchler, M., Huber, J., Stöckl, T., 2012. Thar she bursts: Reducing confusion reduces bubbles. American Economic Review 102, 865-83.

Kopányi, D., Rabanal, J.P., Rud, O.A., Tuinstra, J., 2019. Can competition between forecasters stabilize asset prices in learning to forecast experiments? Journal of Economic Dynamics \& Control 109, 103770.

Kopányi-Peuker, A., Weber, M., 2019. Experience does not eliminate bubbles: Experimental evidence. University of St. Gallen, School of Finance Research Paper 2018/22.

Malmendier, U., Nagel, S., 2011. Depression babies: Do macroeconomic experiences affect risk taking? The Quarterly Journal of Economics 126, 373-416.

Malmendier, U., Nagel, S., 2016. Learning from inflation experiences. The Quarterly Journal of Economics 131, 53-87.

Marimon, R., Spear, S.E., Sunder, S., 1993. Expectationally driven market volatility: An experimental study. Journal of Economic Theory 61, 74-103.

Palan, S., 2013. A review of bubbles and crashes in experimental asset markets. Journal of Economic Surveys 27, 570-588. 
Patton, A.J., Timmermann, A., 2010. Why do forecasters disagree? Lessons from the term structure of cross-sectional dispersion. Journal of Monetary Economics $57,803-820$.

Razen, M., Huber, J., Kirchler, M., 2017. Cash inflow and trading horizon in asset markets. European Economic Review 92, 359-384.

Sonnemans, J., Tuinstra, J., 2010. Positive expectations feedback experiments and number guessing games as models of financial markets. Journal of Economic Psychology 31, 964-984.

Stöckl, T., Huber, J., Kirchler, M., 2010. Bubble measures in experimental asset markets. Experimental Economics 13, 284-298.

Tirole, J., 1982. On the possibility of speculation under rational expectations. Econometrica 50, 1163-1181.

Tirole, J., 1985. Asset bubbles and overlapping generations. Econometrica 53, 1499-1528. 


\section{APPENDIX}

\section{A An asset pricing model with different invest- ment horizons}

\section{A.1 A generalization of the standard asset pricing model}

Following Brock and Hommes (1998), we consider a market populated by a number of investors, e.g., institutional investors, such as pension funds. These investors maximize their wealth by investing in two assets, a risk-free asset and a risky asset. The supply of the risk-free asset is infinitely elastic, and this asset gives a fixed net return of $r$ per period. We denote gross return of this risk-free asset by $R=1+r$. The risky asset pays stochastic dividend $y_{t}$ in period $t$ and its price $p_{t}$, which may vary over time, follows from temporary equilibrium between demand and supply in period $t$.

We extend the model in Brock and Hommes (1998) by allowing investors to differ in their investment horizons. Let us denote the wealth of investor $i$ in period $t$ by $W_{t, i}$. Suppose this investor has investment horizon $h$, i.e., a portfolio should maximize wealth in period $t+h$. Investor $i$ 's wealth in period $t+h$ is given by

$$
\begin{aligned}
W_{t+h, i} & =\left(1-x_{t, i}\right) W_{t, i} R^{h}+x_{t, i} \frac{W_{t, i}}{p_{t}}\left(p_{t+h}+\sum_{s=1}^{h} R^{h-s} y_{t+s}\right) \\
& =W_{t, i} R^{h}+\left(p_{t+h}+\sum_{s=1}^{h} R^{h-s} y_{t+s}-R^{h} p_{t}\right) z_{t, i}
\end{aligned}
$$

where $x_{t, i}$ is the share of the investor's wealth invested in the risky asset, so that $z_{t, i}=x_{t, i} W_{t, i} / p_{t}$ are the investor's holdings of the risky asset bought at time $t$. In expression (A.1), it is assumed that all dividends are automatically reinvested in the risk-free asset every period.

Following Brock and Hommes (1998), we assume that all investors with investment horizon $h$ are mean-variance maximizers with risk aversion parameter $a$ and belief about the conditional variance of excess return (over $h$ periods) given by $\sigma_{h}^{2}$. The optimal amount of the risky asset to be purchased by an investor with horizon $h$, given return expectations, is then

$$
z_{t, i, h}=\frac{\mathrm{E}_{t, i, h}\left(p_{t+h}+\sum_{s=1}^{h} R^{h-s} y_{t+s}-R^{h} p_{t}\right)}{a \sigma_{h}^{2}},
$$

where $\mathrm{E}_{t, i, h}[\cdot]$ stands for the expectations that investor $i$ holds, in period $t$, about future prices and dividends. The notation stresses that the expectations may be heterogeneous even for investors with the same horizon, and that expectations are formed at time $t$. 
The asset price at period $t$ is found from the equilibrium between the total demand, i.e., the sum of individual demands by all institutional investors (with different investment horizons) in the market, and supply, which is assumed to fluctuate randomly, due to noise traders, around the zero mean. ${ }^{29}$ The temporary market equilibrium equation reads

$$
\sum_{i, h} z_{t, i, h}=\sum_{h} \frac{1}{a \sigma_{h}^{2}}\left(\sum_{i} \mathrm{E}_{t, i, h}\left[p_{t+h}\right]+\sum_{i} \sum_{s=1}^{h} R^{h-s} \mathrm{E}_{t, i, h}\left[y_{t+s}\right]-N_{h} R^{h} p_{t}\right)=\epsilon_{t}
$$

where $N_{h}$ represents the number of investors with investment horizon $h$. Dividing this equation by the total number of investors, $N=\sum_{h} N_{h}$, we obtain

$$
\sum_{h} \frac{f_{h}}{N_{h}} \sum_{i}\left(\mathrm{E}_{t, i, h}\left[p_{t+h}\right]+\sum_{s=1}^{h} R^{h-s} \mathrm{E}_{t, i, h}\left[y_{t+s}\right]\right)-\sum_{h} f_{h} R^{h} p_{t}=\varepsilon_{t}
$$

where the 'adjusted' fraction of investors with horizon $h$ is $f_{h}=N_{h} /\left(a \sigma_{h}^{2} N\right)$, and the normalized supply from the noise traders is $\varepsilon_{t}=\epsilon_{t} / N$. From this, it immediately follows that the market clearing price is given as:

$$
p_{t}=\frac{1}{\sum_{h} f_{h} R^{h}}\left(\sum_{h} \frac{f_{h}}{N_{h}} \sum_{i}\left(\mathrm{E}_{t, i, h}\left[p_{t+h}\right]+\sum_{s=1}^{h} R^{h-s} \mathrm{E}_{t, i, h}\left[y_{t+s}\right]\right)-\varepsilon_{t}\right) .
$$

\section{A.2 Asset prices in the laboratory experiment}

To use (A.2) as the price generating mechanism for the laboratory experiment, we make two further assumptions. First, we assume that the dividend process is IID with mean value $\bar{y}$, which is known to all investors. This implies that the stream of expected dividend payments can be computed as:

$$
\sum_{s=1}^{h} R^{h-s} \mathrm{E}_{t, i, h}\left[y_{t+s}\right]=\bar{y} \frac{R^{h}-1}{R-1}=\frac{\bar{y}}{r}\left(R^{h}-1\right) .
$$

We define the fundamental price as the constant price solution under the assumption that all investors have rational expectations, i.e., $\mathrm{E}_{t, i, h}\left[p_{t+h}\right]=p_{t+h}$, for all $t$, $i$ and $h$, and the total supply of noise traders is zero. Under this assumption, the pricing equation (A.2) becomes

$$
p_{t}=\frac{1}{\sum_{h} f_{h} R^{h}} \sum_{h} f_{h}\left(p_{t+h}+\frac{\bar{y}}{r}\left(R^{h}-1\right)\right) .
$$

Then it is straight-forward to check that the fundamental price is $p^{f}=\bar{y} / r$, i.e., it is equal to the discounted sum of all future expected dividends, and is independent of the distribution of traders over the different investment horizons.

\footnotetext{
${ }^{29}$ The assumption that, on average, there is no outside supply of the risky asset, is standard in the literature, see, e.g., Brock and Hommes (1998).
} 
Second, in this paper we focus on the case where all $N$ investors have the same horizon $H$. Pricing equation (A.2) then simplifies to

$$
p_{t}=\frac{1}{R^{H}}\left(\frac{1}{N} \sum_{i} \mathrm{E}_{t, i}\left[p_{t+H}\right]+\bar{y}\left(\frac{R^{H}-1}{R-1}\right)-\varepsilon_{t}\right),
$$

which, using fundamental price $p^{f}=\bar{y} / r$, can be further rewritten as

$$
p_{t}=p^{f}+\frac{1}{R^{H}}\left(\frac{1}{N} \sum_{i=1}^{N} \mathrm{E}_{t, i}\left[p_{t+H}\right]-p^{f}-\varepsilon_{t}\right) .
$$

This equation defines the market-clearing price in period $t$ that we use in the experiment, see Eq. (1) in the main text. In the experiment we implement Eq. (A.3) with $N=6$ (the size of the group), $H=1,2$ and 3 (values of the investment horizon in different treatments), $p^{f}=60$ and $R=1.05$ or, in treatment OscH3SF, $R=1.016$, see Table 1 . Note that the fundamental price, $p^{f}=\bar{y} / r$, is the rational expectation solution of (A.3) regardless of the values of the parameters.

We note that, in the absence of noise traders (i.e., when $\varepsilon_{t}=0$ for all $t$ ) other rational expectations equilibria, so-called rational bubbles, exist in this model. Such a rational bubble is an equilibrium where traders expect the deviation of the asset price from the fundamental value to grow with a factor $R$ each period. That is, if $p_{0}>p^{f}$ and expectations of all traders at time $t$ are given by

$$
\mathrm{E}_{t, i}\left[p_{t+H}\right]=p^{f}+R^{H+1}\left(p_{t-1}-p^{f}\right),
$$

then substituting these expectations in (A.3), we derive that the price in period $t$ is $p_{t}=p^{f}+R\left(p_{t-1}-p^{f}\right)$, confirming the expectation scheme. Hommes et al. (2008) study the experimental bubbles and reject that they correspond to the rational bubbles.

\section{B Experimental Instructions}

Instructions below were distributed to all subjects participating in the OscH3SF treatment. The wording of the instructions in all other treatments is the same. The instructions are only adjusted to the corresponding investment horizon and the specific values of parameters $r$ and $\bar{y}$ used in a treatment, see Table 1.

\section{INSTRUCTIONS}

\section{General information}

Today you will participate in an experiment which will require you to predict the future price of a risky asset. During the experiment you will be able to earn a number of points. The better your predictions are, the more points will you earn. These points will be converted into Australian dollars after the experiment. 


\section{Information about your task}

You are a financial forecaster working for a pension fund that wants to optimally invest a large amount of money for 3 periods. The pension fund has two investment options: a risk-free investment and a risky investment. The risk-free investment is putting money in a savings account, which pays a fixed and constant interest rate over 3 periods. The alternative for the pension fund is to invest its money in a risky asset, where risk comes from the uncertain future price of that asset.

In each period the pension fund has to decide which fraction of its money to put in the savings account and which fraction of its money to invest in the risky asset. To make the optimal investment decision, the pension fund needs an accurate prediction of the future price of the asset. The pension fund is only interested in the price of the risky asset after 3 periods.

As the financial forecaster of the fund, you have to predict the price for the risky asset 3 periods ahead during 53 subsequent periods. Your earnings during the experiment depend upon the accuracy of your predictions. The smaller your errors in each period are, the higher your total earnings will be.

\section{Information about the asset market}

The market price of the risky asset in each period is determined by demand and supply. The total supply of assets is fixed during the experiment. The demand for assets is mainly determined by the aggregate demand of several large pension funds active in the asset market. There is also some uncertain, small demand for assets by private investors but the effect of private investors upon the asset price is small.

\section{Information about the investment strategies of the pension funds}

The precise investment strategy of the pension fund that you are advising and the investment strategies of the other pension funds are unknown. The savings account, that provides the risk-free investment, pays a fixed interest rate of $1.6 \%$ per period. The owner of the risky asset receives an uncertain payment in each period, but economic experts have computed that this payment is 0.96 dollars per period on average. The return of the asset market per period depends upon these payments as well as upon price changes of the asset.

As the financial forecaster of a pension fund you are only asked to predict, in each period, the 3 periods ahead price of the asset. Based upon your future price predictions, your pension fund will make an optimal investment decision and hold the asset for 3 periods. The higher your predicted future price is, the larger will be the fraction of money invested by your pension fund in the asset market in the current period, so the larger will be its demand for assets.

\section{Information during the experiment}

At the beginning of the experiment, you have the history of the asset price in the first 10 periods, and you start in period 11 by giving your prediction of the price 
in period 14. After all participants have given their predictions, the realized asset price for period 11 will be revealed. Then you (as all other participants) will need to make a new prediction, now for the price in period 15, so that the asset price for period 12 can be defined. And so on. This process continues until period 63, where the last prediction, for the price in period 66, will be given.

To predict the asset price for period $t+3$ in period $t$, the available information consists of

- past prices up to period $t-1$,

- your previous predictions up to period $t+2$,

- your past earnings up to period $t-1$.

Starting from period 14, your earnings in each period will be based upon your prediction error, that is, the difference between the price you predicted for that period and the realized price in that period. The last period for which you will be paid is period 63 .

The better you predict the asset price in each period, the higher your aggregate earnings will be. Earnings for each period in points will be automatically computed according to the following earnings table, where "error" denotes the absolute value of the difference between your prediction and price in that period. Information on your earnings in the current period and cumulative earnings will be reported to you during the experiment.

After the experiment your earned points will be converted into Australian dollars, with 1300 points equal to 50 cents. You will be paid the sum of show-up fee and all your earnings in AUD.

\begin{tabular}{|r|l|r|l|r|l|r|r|r|r|}
\hline \multicolumn{10}{|c|}{ Earnings table } \\
\hline Error & Points & Error & Points & Error & Points & Error & Points & Error & Points \\
\hline $\mathbf{0 . 1}$ & 1300 & $\mathbf{1 . 5}$ & 1240 & $\mathbf{2 . 9}$ & 1077 & $\mathbf{4 . 3}$ & 809 & $\mathbf{5 . 7}$ & 438 \\
\hline $\mathbf{0 . 2}$ & 1299 & $\mathbf{1 . 6}$ & 1232 & $\mathbf{3}$ & 1061 & $\mathbf{4 . 4}$ & 786 & $\mathbf{5 . 8}$ & 408 \\
\hline $\mathbf{0 . 3}$ & 1298 & $\mathbf{1 . 7}$ & 1223 & $\mathbf{3 . 1}$ & 1045 & $\mathbf{4 . 5}$ & 763 & $\mathbf{5 . 9}$ & 376 \\
\hline $\mathbf{0 . 4}$ & 1296 & $\mathbf{1 . 8}$ & 1214 & $\mathbf{3 . 2}$ & 1028 & $\mathbf{4 . 6}$ & 739 & $\mathbf{6}$ & 345 \\
\hline $\mathbf{0 . 5}$ & 1293 & $\mathbf{1 . 9}$ & 1204 & $\mathbf{3 . 3}$ & 1011 & $\mathbf{4 . 7}$ & 714 & $\mathbf{6 . 1}$ & 313 \\
\hline $\mathbf{0 . 6}$ & 1290 & $\mathbf{2}$ & 1194 & $\mathbf{3 . 4}$ & 993 & $\mathbf{4 . 8}$ & 689 & $\mathbf{6 . 2}$ & 280 \\
\hline $\mathbf{0 . 7}$ & 1287 & $\mathbf{2 . 1}$ & 1183 & $\mathbf{3 . 5}$ & 975 & $\mathbf{4 . 9}$ & 663 & $\mathbf{6 . 3}$ & 247 \\
\hline $\mathbf{0 . 8}$ & 1283 & $\mathbf{2 . 2}$ & 1172 & $\mathbf{3 . 6}$ & 956 & $\mathbf{5}$ & 637 & $\mathbf{6 . 4}$ & 213 \\
\hline $\mathbf{0 . 9}$ & 1279 & $\mathbf{2 . 3}$ & 1160 & $\mathbf{3 . 7}$ & 937 & $\mathbf{5 . 1}$ & 610 & $\mathbf{6 . 5}$ & 179 \\
\hline $\mathbf{1}$ & 1273 & $\mathbf{2 . 4}$ & 1147 & $\mathbf{3 . 8}$ & 917 & $\mathbf{5 . 2}$ & 583 & $\mathbf{6 . 6}$ & 144 \\
\hline $\mathbf{1 . 1}$ & 1268 & $\mathbf{2 . 5}$ & 1134 & $\mathbf{3 . 9}$ & 896 & $\mathbf{5 . 3}$ & 555 & $\mathbf{6 . 7}$ & 109 \\
\hline $\mathbf{1 . 2}$ & 1262 & $\mathbf{2 . 6}$ & 1121 & $\mathbf{4}$ & 876 & $\mathbf{5 . 4}$ & 526 & $\mathbf{6 . 8}$ & $\mathbf{7 3}$ \\
\hline $\mathbf{1 . 3}$ & 1255 & $\mathbf{2 . 7}$ & 1107 & $\mathbf{4 . 1}$ & 854 & $\mathbf{5 . 5}$ & 497 & $\mathbf{6 . 9}$ & 37 \\
\hline $\mathbf{1 . 4}$ & 1248 & $\mathbf{2 . 8}$ & 1092 & $\mathbf{4 . 2}$ & 832 & $\mathbf{5 . 6}$ & 468 & $\mathbf{7}$ or $\mathbf{m o r e}$ & 0 \\
\hline
\end{tabular}

\section{Additional information}


- By the end of the experiment, you will be paid privately. Before the payment you will be asked to answer a questionnaire. Inserted data will be processed in nameless form only. Please fill in the correct information.

- During the experiment any communication with other participants, whether verbal or written, is forbidden. The use of phones, tablets or any other gadgets is not allowed. Violation of the rules can result in exclusion from the experiment without any remuneration.

- Please follow the instructions carefully at all the stages of the experiment. If you have any questions or encounter any problems during the experiment, please raise your hand and the experimenter will come to help you.

Please ask any questions you have now! 


\section{Descriptive statistics, tests, estimations}

\section{C.1 Descriptive statistics}

\begin{tabular}{|c|c|c|c|c|c|c|c|}
\hline Treatment & Group & $\begin{array}{r}\text { Mean } \\
\text { price }\end{array}$ & $\begin{array}{l}\text { Std } \\
\text { dev }\end{array}$ & $\begin{array}{r}\text { Median } \\
\text { RAD }\end{array}$ & IQR & Discoord & $\begin{array}{r}\text { Average } \\
\text { payoffs }\end{array}$ \\
\hline \multirow{5}{*}{ ConH1 } & Group 1 & 57.67 & 2.07 & 0.04 & 3.36 & 0.66 & 1221.2 \\
\hline & Group 2 & 58.69 & 0.99 & 0.02 & 1.23 & 0.28 & 1272.4 \\
\hline & Group 3 & 58.23 & 3.65 & 0.02 & 3.72 & 0.46 & 1226.5 \\
\hline & Average & 58.20 & 2.24 & 0.02 & 2.77 & 0.46 & 930.0 \\
\hline & Median & 58.23 & 2.07 & 0.02 & 3.36 & 0.46 & 1223.8 \\
\hline \multirow{6}{*}{ ConH2 } & Group 1 & 56.63 & 0.99 & 0.05 & 1.35 & 1.01 & 1198.9 \\
\hline & Group 2 & 64.33 & 14.34 & 0.04 & 3.99 & 1.97 & 857.6 \\
\hline & Group 3 & 59.37 & 1.08 & 0.01 & 0.81 & 0.70 & 1215.5 \\
\hline & Group 4 & 59.08 & 0.70 & 0.01 & 0.88 & 0.68 & 1241.1 \\
\hline & Average & 59.85 & 4.28 & 0.03 & 1.76 & 1.09 & 1128.3 \\
\hline & Median & 59.22 & 1.04 & 0.03 & 1.12 & 0.86 & 1207.2 \\
\hline \multirow{5}{*}{ ConH3 } & Group 1 & 63.46 & 1.28 & 0.06 & 1.47 & 2.12 & 1016.7 \\
\hline & Group 2 & 58.96 & 1.24 & 0.02 & 1.82 & 1.31 & 1121.6 \\
\hline & Group 3 & 59.76 & 0.62 & 0.00 & 0.80 & 0.62 & 1252.2 \\
\hline & Average & 60.73 & 1.05 & 0.03 & 1.36 & 1.35 & 1130.2 \\
\hline & Median & 59.76 & 1.24 & 0.02 & 1.47 & 1.31 & 1121.6 \\
\hline \multirow{10}{*}{ OscH1 } & Group 1 & 63.28 & 1.26 & 0.05 & 0.86 & 0.37 & 1266.0 \\
\hline & Group 2 & 60.64 & 1.64 & 0.02 & 2.76 & 0.88 & 1223.5 \\
\hline & Group 3 & 52.25 & 23.91 & 0.36 & 42.42 & 5.24 & 494.7 \\
\hline & Group 4 & 63.85 & 6.96 & 0.08 & 6.48 & 1.39 & 946.3 \\
\hline & Group 5 & 61.30 & 1.07 & 0.02 & 0.99 & 0.35 & 1266.9 \\
\hline & Group 6 & 72.25 & 45.16 & 0.49 & 76.90 & 5.44 & 382.9 \\
\hline & Group 7 & 231.63 & 305.74 & 0.47 & 268.87 & 6.18 & 475.5 \\
\hline & Group 8 & 67.64 & 57.04 & 0.11 & 16.78 & 0.87 & 909.5 \\
\hline & Average & 84.10 & 55.35 & 0.20 & 52.01 & 2.59 & 870.7 \\
\hline & Median & 63.57 & 15.43 & 0.10 & 11.63 & 1.14 & 927.9 \\
\hline \multirow{7}{*}{ OscH2 } & Group 1 & 54.84 & 6.76 & 0.11 & 8.98 & 4.94 & 413.5 \\
\hline & Group 2 & 51.93 & 18.56 & 0.16 & 23.67 & 5.27 & 332.3 \\
\hline & Group 3 & 58.42 & 14.08 & 0.14 & 15.99 & 6.29 & 279.0 \\
\hline & Group 4 & 60.32 & 11.83 & 0.19 & 23.46 & 5.67 & 213.5 \\
\hline & Group 5 & 57.84 & 13.09 & 0.16 & 19.86 & 9.79 & 149.9 \\
\hline & Average & 56.67 & 12.86 & 0.15 & 18.39 & 6.39 & 231.4 \\
\hline & Median & 57.84 & 13.09 & 0.16 & 19.86 & 5.67 & 246.3 \\
\hline \multirow{8}{*}{ OscH3 } & Group 1 & 60.47 & 2.18 & 0.02 & 2.40 & 2.50 & 977.6 \\
\hline & Group 2 & 67.57 & 12.73 & 0.09 & 2.49 & 2.76 & 791.4 \\
\hline & Group 3 & 60.56 & 2.57 & 0.03 & 3.66 & 1.77 & 813.4 \\
\hline & Group 4 & 54.37 & 11.12 & 0.12 & 10.90 & 10.31 & 270.6 \\
\hline & Group 5 & 61.33 & 4.60 & 0.03 & 2.28 & 3.89 & 766.6 \\
\hline & Group 6 & 58.57 & 3.61 & 0.02 & 2.20 & 1.53 & 907.9 \\
\hline & Average & 60.48 & 6.14 & 0.05 & 3.99 & 3.79 & 754.6 \\
\hline & Median & 60.52 & 4.11 & 0.03 & 2.44 & 2.63 & 802.4 \\
\hline \multirow{8}{*}{ OscH3SF } & Group 1 & 61.02 & 3.34 & 0.02 & 1.69 & 0.60 & 776.8 \\
\hline & Group 2 & 60.72 & 0.97 & 0.01 & 1.02 & 0.88 & 1192.8 \\
\hline & Group 3 & 59.76 & 15.61 & 0.14 & 17.11 & 7.21 & 284.2 \\
\hline & Group 4 & 55.73 & 1.82 & 0.07 & 2.24 & 2.21 & 1022.2 \\
\hline & Group 5 & 50.60 & 19.54 & 0.19 & 21.05 & 11.96 & 206.4 \\
\hline & Group 6 & 45.10 & 14.72 & 0.23 & 17.31 & 8.61 & 249.0 \\
\hline & Average & 55.49 & 9.33 & 0.11 & 10.07 & 5.25 & 621.9 \\
\hline & Median & 57.74 & 9.03 & 0.11 & 9.68 & 4.71 & 530.5 \\
\hline
\end{tabular}

Table 2: Descriptive statistics in the experiment. 


\section{C.2 Nonparametric test for median of RAD comparison}

\begin{tabular}{l|ccccccc}
\hline Median RAD & ConH1 & ConH2 & ConH3 & OscH1 & OscH2 & OscH3 & OscH3SF \\
\hline ConH1 & $\mathrm{X}$ & 0.616 & 0.320 & $0.086^{*}$ & $0.014^{* *}$ & 0.534 & 0.198 \\
ConH2 & & $\mathrm{X}$ & 0.961 & 0.150 & $0.007^{* * *}$ & 0.435 & 0.135 \\
ConH3 & & & $\mathrm{X}$ & 0.167 & $0.014^{* *}$ & 0.198 & 0.198 \\
OscH1 & & & & $\mathrm{X}$ & 0.305 & 0.471 & 0.608 \\
OscH2 & & & & & $\mathrm{X}$ & $0.018^{* *}$ & 0.367 \\
OscH3 & & & & & & $\mathrm{X}$ & 0.318 \\
OscH3SF & & & & & & & $\mathrm{X}$ \\
\hline
\end{tabular}

Table 3: p-values of the two-sided Kolmogorov-Smirnov test comparing the median of RAD statistics, pairwise for different treatments. *, **, and *** denote treatment comparisons when the null hypothesis of equality is rejected at the $10 \%$, $5 \%$ or $1 \%$ significance level, respectively.

\begin{tabular}{l|ccccccc}
\hline Median RAD & ConH1 & ConH2 & ConH3 & OscH1 & OscH2 & OscH3 & OscH3SF \\
\hline ConH1 & $\mathrm{X}$ & 0.662 & 0.889 & 0.155 & $0.005^{* * *}$ & 0.379 & 0.166 \\
ConH2 & & $\mathrm{X}$ & 0.806 & 0.103 & $0.005^{* * *}$ & 0.417 & 0.114 \\
ConH3 & & & $\mathrm{X}$ & 0.193 & $0.024^{* *}$ & 0.388 & 0.188 \\
OscH1 & & & & $\mathrm{X}$ & 0.592 & 0.119 & 0.335 \\
OscH2 & & & & & $\mathrm{X}$ & $0.008^{* * *}$ & 0.369 \\
OscH3 & & & & & & $\mathrm{X}$ & 0.178 \\
OscH3SF & & & & & & & $\mathrm{X}$ \\
\hline
\end{tabular}

Table 4: p-values of the Fischer-Pitman permutation test comparing the median of RAD statistics, pairwise for different treatments. *, **, and *** denote treatment comparisons when the null hypothesis of equality is rejected at the $10 \%, 5 \%$ or $1 \%$ significance level, respectively.

\begin{tabular}{l|ccccccc}
\hline Median RAD & ConH1 & ConH2 & ConH3 & OscH1 & OscH2 & OscH3 & OscH3SF \\
\hline ConH1 & $\mathrm{X}$ & 1.000 & 0.700 & $0.085^{*}$ & $0.036^{* *}$ & 0.381 & 0.548 \\
ConH2 & & $\mathrm{X}$ & 1.000 & $0.073^{*}$ & $0.016^{* *}$ & 0.476 & 0.114 \\
ConH3 & & & $\mathrm{X}$ & $0.085^{*}$ & $0.036^{* *}$ & 0.262 & 0.262 \\
OscH1 & & & & $\mathrm{X}$ & 0.622 & 0.282 & 0.491 \\
OscH2 & & & & & $\mathrm{X}$ & $0.009^{* * *}$ & 0.662 \\
OscH3 & & & & & & $\mathrm{X}$ & 0.589 \\
OscH3SF & & & & & & & $\mathrm{X}$ \\
\hline
\end{tabular}

Table 5: p-values of the Mann-Whitney-Wilcoxon test comparing the median of RAD statistics, pairwise for different treatments. ${ }^{*}, * *$, and $* * *$ denote treatment comparisons when the null hypothesis of equality is rejected at the $10 \%, 5 \%$ or $1 \%$ significance level, respectively. 


\section{C.3 Nonparametric test for IQR comparison}

\begin{tabular}{l|ccccccc}
\hline IQR & ConH1 & ConH2 & ConH3 & OscH1 & OscH2 & OscH3 & OscH3SF \\
\hline ConH1 & $\mathrm{X}$ & 0.616 & 0.320 & 0.225 & $0.014^{* *}$ & 0.935 & 0.534 \\
ConH2 & & $\mathrm{X}$ & 0.821 & 0.150 & $0.007^{* * *}$ & $0.066^{*}$ & 0.254 \\
ConH3 & & & $\mathrm{X}$ & $0.086^{*}$ & $0.014^{* *}$ & $0.011^{* *}$ & 0.198 \\
OscH1 & & & & $\mathrm{X}$ & 0.305 & 0.254 & 0.608 \\
OscH2 & & & & & $\mathrm{X}$ & $0.018^{* *}$ & 0.367 \\
OscH3 & & & & & & $\mathrm{X}$ & 0.318 \\
OscH3SF & & & & & & & $\mathrm{X}$ \\
\hline
\end{tabular}

Table 6: p-values of the two-sided Kolmogorov-Smirnov test comparing the interquartile range statistics, pairwise for different treatments. *,**, and $* * *$ denote treatment comparisons when the null hypothesis of equality is rejected at the $10 \%, 5 \%$ or $1 \%$ significance level, respectively.

\begin{tabular}{l|ccccccc}
\hline IQR & ConH1 & ConH2 & ConH3 & OscH1 & OscH2 & OscH3 & OscH3SF \\
\hline ConH1 & $\mathrm{X}$ & 0.352 & 0.194 & 0.452 & $0.024^{* *}$ & 0.763 & 0.256 \\
ConH2 & & $\mathrm{X}$ & 0.889 & 0.321 & $0.014^{* *}$ & 0.308 & 0.114 \\
ConH3 & & & $\mathrm{X}$ & 0.319 & $0.012^{* *}$ & 0.247 & 0.224 \\
OscH1 & & & & $\mathrm{X}$ & 0.631 & 0.208 & 0.342 \\
OscH2 & & & & & $\mathrm{X}$ & $0.005^{* * *}$ & 0.122 \\
OscH3 & & & & & & $\mathrm{X}$ & 0.178 \\
OscH3SF & & & & & & & $\mathrm{X}$ \\
\hline
\end{tabular}

Table 7: p-values of the Fischer-Pitman permutation test comparing the interquartile range statistics, pairwise for different treatments. $*, * *$, and $* * *$ denote treatment comparisons when the null hypothesis of equality is rejected at the $10 \%, 5 \%$ or $1 \%$ significance level, respectively.

\begin{tabular}{l|ccccccc}
\hline IQR & ConH1 & ConH2 & ConH3 & OscH1 & OscH2 & OscH3 & OscH3SF \\
\hline ConH1 & $\mathrm{X}$ & 0.629 & 0.400 & 0.497 & $0.036^{* *}$ & 1.000 & 0.714 \\
ConH2 & & $\mathrm{X}$ & 1.000 & 0.109 & $0.016^{* *}$ & 0.171 & 0.114 \\
ConH3 & & & $\mathrm{X}$ & 0.133 & $0.036^{* *}$ & $0.022^{* *}$ & 0.167 \\
OscH1 & & & & $\mathrm{X}$ & 0.724 & 0.282 & 0.755 \\
OscH2 & & & & & $\mathrm{X}$ & $0.009^{* * *}$ & 0.177 \\
OscH3 & & & & & & $\mathrm{X}$ & 0.937 \\
OscH3SF & & & & & & & $\mathrm{X}$ \\
\hline
\end{tabular}

Table 8: p-values of the Mann-Whitney-Wilcoxon test comparing the interquartile range statistics, pairwise for different treatments. ${ }^{*},{ }^{* *}$, and $* * *$ denote treatment comparisons when the null hypothesis of equality is rejected at the $10 \%, 5 \%$ or $1 \%$ significance level, respectively. 


\section{C.4 Estimated AR(2) Rules}

\begin{tabular}{|c|c|c|c|c|c|c|c|c|}
\hline \multirow[t]{2}{*}{ Treatment } & \multirow[t]{2}{*}{ Group } & \multirow[t]{2}{*}{ Const } & \multicolumn{2}{|c|}{ Past Prices } & \multicolumn{2}{|c|}{ Specification Tests } & \multirow[t]{2}{*}{ AdjRSq } & \multirow[t]{2}{*}{ NObs } \\
\hline & & & & $\operatorname{lag} 2$ & & & & \\
\hline \multirow[t]{3}{*}{ ConH1 } & & $\begin{array}{c}17.72^{* * *} \\
(2.55)\end{array}$ & $\begin{array}{c}1.54^{* * * *} \\
(0.08)\end{array}$ & $\begin{array}{c}-0.85^{* * *} \\
(0.08)\end{array}$ & 0.71 & 0.35 & 0.92 & 48 \\
\hline & Group 2 & $\begin{array}{c}18.66^{* * *} \\
(4.24)\end{array}$ & $\begin{array}{c}1.32^{* * *} \\
(0.11)\end{array}$ & $\begin{array}{c}-0.64^{* * *} \\
(0.11)\end{array}$ & 0.68 & 0.70 & 0.78 & 48 \\
\hline & Group 3 & $\begin{array}{c}5.41^{* * *} \\
(1.39)\end{array}$ & $\begin{array}{c}1.37^{* * *} \\
(0.12)\end{array}$ & $\begin{array}{c}-0.46^{* * *} \\
(0.11)\end{array}$ & 0.34 & 0.24 & 0.97 & 48 \\
\hline \multirow[t]{4}{*}{ ConH2 } & Group 1 & $\begin{array}{c}40.99^{* * *} \\
(6.05)\end{array}$ & $\begin{array}{c}0.90^{* * * *} \\
(0.12)\end{array}$ & $\begin{array}{c}-0.62^{* * * *} \\
(0.11)\end{array}$ & 0.13 & 0.25 & 0.57 & 48 \\
\hline & Group 2 & $\begin{array}{c}45.76^{* * *} \\
(10.70)\end{array}$ & $\begin{array}{c}0.44^{* * *} \\
(0.15)\end{array}$ & $\begin{array}{l}-0.15 \\
(0.15)\end{array}$ & 1.00 & 0.88 & 0.13 & 48 \\
\hline & Group 3 & $\begin{array}{c}53.60^{* * *} \\
(9.24)\end{array}$ & $\begin{array}{c}0.49^{* * *} \\
(0.14)\end{array}$ & $\begin{array}{c}-0.39^{* * *} \\
(0.14)\end{array}$ & 0.99 & 0.54 & 0.23 & 48 \\
\hline & Group 4 & $\begin{array}{c}52.03^{* * *} \\
(8.32)\end{array}$ & $\begin{array}{c}0.54^{* * *} \\
(0.13)\end{array}$ & $\begin{array}{c}-0.42^{* * *} \\
(0.13)\end{array}$ & 0.74 & 0.43 & 0.28 & 48 \\
\hline \multirow[t]{3}{*}{ ConH3 } & Group 1 & $\begin{array}{c}35.45^{* * *} \\
(7.24)\end{array}$ & $\begin{array}{c}0.91 * * * \\
(0.13)\end{array}$ & $\begin{array}{c}-0.47^{* * *} \\
(0.13)\end{array}$ & 0.51 & 0.57 & 0.51 & 48 \\
\hline & Group 2 & $\begin{array}{c}27.81^{* * *} \\
(4.80)\end{array}$ & $\begin{array}{c}1.21^{* * *} \\
(0.11)\end{array}$ & $\begin{array}{c}-0.69^{* * *} \\
(0.11)\end{array}$ & 0.69 & 0.54 & 0.73 & 48 \\
\hline & Group 3 & $\begin{array}{c}46.64^{* * *} \\
(9.50)\end{array}$ & $\begin{array}{c}0.48^{* * *} \\
(0.14)\end{array}$ & $\begin{array}{c}-0.26^{*} \\
(0.14)\end{array}$ & 0.32 & 0.07 & 0.17 & 48 \\
\hline \multirow[t]{8}{*}{ OscH1 } & Group 1 & $\begin{array}{c}9.05^{* * *} \\
(3.13)\end{array}$ & $\begin{array}{c}1.34^{* * * *} \\
(0.13)\end{array}$ & $\begin{array}{c}-0.48^{* * *} \\
(0.12)\end{array}$ & 0.42 & 0.88 & 0.87 & 48 \\
\hline & Group 2 & $\begin{array}{c}11.66^{* * *} \\
(3.71)\end{array}$ & $\begin{array}{c}1.34^{* * * *} \\
(0.12)\end{array}$ & $\begin{array}{c}-0.53^{* * *} \\
(0.12)\end{array}$ & 0.81 & 0.39 & 0.84 & 48 \\
\hline & Group 3 & $\begin{array}{c}16.87^{* * *} \\
(2.68)\end{array}$ & $\begin{array}{c}1.53^{* * *} \\
(0.08)\end{array}$ & $\begin{array}{c}-0.85^{* * *} \\
(0.08)\end{array}$ & 0.01 & 0.31 & 0.91 & 48 \\
\hline & Group 4 & $\begin{array}{c}25.34^{* * *} \\
(1.29)\end{array}$ & $\begin{array}{c}1.76^{* * * *} \\
(0.04)\end{array}$ & $\begin{array}{c}-1.16^{* * *} \\
(0.04)\end{array}$ & 0.06 & 0.85 & 0.98 & 48 \\
\hline & Group 5 & $\begin{array}{c}12.36^{* * *} \\
(4.19)\end{array}$ & $\begin{array}{c}1.14 * * * \\
(0.14)\end{array}$ & $\begin{array}{c}-0.34^{* *} \\
(0.13)\end{array}$ & 0.66 & 0.52 & 0.76 & 48 \\
\hline & Group 6 & $\begin{array}{c}12.29^{* * *} \\
(1.48)\end{array}$ & $\begin{array}{c}1.86^{* * * *} \\
(0.04)\end{array}$ & $\begin{array}{c}-1.03^{* * *} \\
(0.04)\end{array}$ & 0.00 & 0.44 & 0.99 & 48 \\
\hline & Group 7 & $\begin{array}{c}29.91^{* *} \\
(11.32)\end{array}$ & $\begin{array}{c}1.76^{* * *} \\
(0.08)\end{array}$ & $\begin{array}{c}-0.88^{* * *} \\
(0.09)\end{array}$ & 0.08 & 0.06 & 0.96 & 48 \\
\hline & Group 8 & $\begin{array}{l}2.56^{* *} \\
(1.13)\end{array}$ & $\begin{array}{c}2.33^{* * *} \\
(0.04)\end{array}$ & $\begin{array}{c}-1.37^{* * *} \\
(0.05)\end{array}$ & 0.92 & 0.55 & 1.00 & 48 \\
\hline \multirow[t]{5}{*}{$\mathrm{OscH} 2$} & Group 1 & $\begin{array}{c}28.23^{* * *} \\
(3.43)\end{array}$ & $\begin{array}{c}1.28^{* * *} \\
(0.08)\end{array}$ & $\begin{array}{c}-0.79^{* * *} \\
(0.08)\end{array}$ & 0.74 & 0.23 & 0.83 & 48 \\
\hline & Group 2 & $\begin{array}{c}25.82^{* * *} \\
(2.85)\end{array}$ & $\begin{array}{c}1.40^{* * * *} \\
(0.07)\end{array}$ & $\begin{array}{c}-0.89^{* * *} \\
(0.07)\end{array}$ & 0.03 & 0.55 & 0.89 & 48 \\
\hline & Group 3 & $\begin{array}{c}28.71^{* * *} \\
(3.95)\end{array}$ & $\begin{array}{c}1.31^{* * *} \\
(0.09)\end{array}$ & $\begin{array}{c}-0.80^{* * *} \\
(0.09)\end{array}$ & 0.01 & 0.00 & 0.82 & 48 \\
\hline & Group 4 & $\begin{array}{c}34.97^{* * *} \\
(3.56)\end{array}$ & $\begin{array}{c}1.28^{* * *} \\
(0.07)\end{array}$ & $\begin{array}{c}-0.86^{* * * *} \\
(0.07)\end{array}$ & 0.09 & 0.02 & 0.86 & 48 \\
\hline & Group 5 & $\begin{array}{c}33.02^{* * *} \\
(4.65)\end{array}$ & $\begin{array}{c}1.19^{* * *} \\
(0.10)\end{array}$ & $\begin{array}{c}-0.76^{* * *} \\
(0.10)\end{array}$ & 0.03 & 0.84 & 0.76 & 48 \\
\hline \multirow[t]{6}{*}{ OscH3 } & Group 1 & $\begin{array}{c}23.33^{* * *} \\
(7.12)\end{array}$ & $\begin{array}{c}0.59^{* * *} \\
(0.15)\end{array}$ & $\begin{array}{c}0.02 \\
(0.14)\end{array}$ & 0.97 & 0.67 & 0.37 & 48 \\
\hline & Group 2 & $\begin{array}{c}47.17^{* * *} \\
(11.37)\end{array}$ & $\begin{array}{c}0.40^{* * * *} \\
(0.15)\end{array}$ & $\begin{array}{l}-0.10 \\
(0.15)\end{array}$ & 1.00 & 0.88 & 0.10 & 48 \\
\hline & Group 3 & $\begin{array}{c}21.56^{* * *} \\
(2.64)\end{array}$ & $\begin{array}{c}1.53^{* * *} \\
(0.07)\end{array}$ & $\begin{array}{c}-0.89^{* * * *} \\
(0.07)\end{array}$ & 0.12 & 0.41 & 0.92 & 48 \\
\hline & Group 4 & $\begin{array}{c}34.48^{* * *} \\
(4.90)\end{array}$ & $\begin{array}{c}0.94^{* * * *} \\
(0.11)\end{array}$ & $\begin{array}{c}-0.56^{* * *} \\
(0.10)\end{array}$ & 0.16 & 0.19 & 0.60 & 48 \\
\hline & Group 5 & $\begin{array}{c}39.42^{* * *} \\
(4.63)\end{array}$ & $\begin{array}{c}0.99^{* * * *} \\
(0.10)\end{array}$ & $\begin{array}{c}-0.63^{* * *} \\
(0.08)\end{array}$ & 0.00 & 0.33 & 0.69 & 48 \\
\hline & Group 6 & $\begin{array}{c}10.59^{* * *} \\
(2.09)\end{array}$ & $\begin{array}{c}1.54^{* * *} \\
(0.09)\end{array}$ & $\begin{array}{c}-0.71^{* * *} \\
(0.09)\end{array}$ & 0.01 & 0.10 & 0.93 & 48 \\
\hline \multirow[t]{6}{*}{ OscH3SF } & Group 1 & $\begin{array}{c}18.98^{* *} \\
(7.16)\end{array}$ & $\begin{array}{c}1.03^{* * *} \\
(0.18)\end{array}$ & $\begin{array}{c}-0.34^{*} \\
(0.18)\end{array}$ & 0.27 & 0.66 & 0.57 & 38 \\
\hline & Group 2 & $\begin{array}{c}38.99^{* * *} \\
(5.56)\end{array}$ & $\begin{array}{c}0.96 * * * \\
(0.11)\end{array}$ & $\begin{array}{c}-0.60^{* * *} \\
(0.10)\end{array}$ & 0.21 & 0.93 & 0.61 & 48 \\
\hline & Group 3 & $\begin{array}{c}26.25^{* * *} \\
(4.61)\end{array}$ & $\begin{array}{c}1.27^{* * *} \\
(0.10)\end{array}$ & $\begin{array}{c}-0.71^{* * * *} \\
(0.10)\end{array}$ & 0.46 & 0.13 & 0.77 & 48 \\
\hline & Group 4 & $\begin{array}{c}21.73^{* * *} \\
(5.12)\end{array}$ & $\begin{array}{c}1.08^{* * * *} \\
(0.12)\end{array}$ & $\begin{array}{c}-0.47^{* * *} \\
(0.11)\end{array}$ & 0.13 & 0.60 & 0.66 & 48 \\
\hline & Group 5 & $\begin{array}{c}30.25^{* * *} \\
(7.03)\end{array}$ & $\begin{array}{c}0.75^{* * *} \\
(0.14)\end{array}$ & $\begin{array}{c}-0.34^{* *} \\
(0.14)\end{array}$ & 1.00 & 0.98 & 0.36 & 48 \\
\hline & Group 6 & $\begin{array}{c}23.44^{* * *} \\
(4.29)\end{array}$ & $\begin{array}{c}1.11^{* * *} \\
(0.11)\end{array}$ & $\begin{array}{c}-0.63^{* * *} \\
(0.11)\end{array}$ & 0.26 & 0.05 & 0.66 & 48 \\
\hline
\end{tabular}

Table 9: Estimated AR(2) rules, Eq. (6), for each experimental group. *, **, and *** for the estimations show significance at the $10 \%, 5 \%$ or $1 \%$ significance level, respectively, with the standard errors shown below in parentheses. Columns 'autoc' and 'hskd' show p-values of the specification tests for the residual autocorrelation (Ljung-Box test) and heteroscedasticity (Engle's ARCH tests), respectively. The group label is in bold when the estimated rule passes both tests at the $5 \%$ significance level. 


\section{C.5 $t$-test for correlations comparison}

\begin{tabular}{l|ccccccc}
\hline Slope & ConH1 & ConH2 & ConH3 & OscH1 & OscH2 & OscH3 & OscH3SF \\
\hline ConH1 & $\mathrm{X}$ & 0.888 & 0.893 & 0.986 & 0.982 & 0.914 & 0.963 \\
ConH2 & & $\mathrm{X}$ & 0.925 & 0.976 & 0.946 & 0.940 & 0.950 \\
ConH3 & & & $\mathrm{X}$ & 0.928 & 0.764 & 0.736 & 0.803 \\
OscH1 & & & & $\mathrm{X}$ & $0.057^{*}$ & $0.048^{* *}$ & $0.052^{*}$ \\
OscH2 & & & & & $\mathrm{X}$ & 0.775 & 0.802 \\
OscH3 & & & & & & $\mathrm{X}$ & 0.535 \\
OscH3SF & & & & & & & $\mathrm{X}$ \\
\hline
\end{tabular}

Table 10: p-values of the $t$-test of the differences in correlations between $\bar{p}_{i, t+h}^{e}-p_{t-1}$ and the price change, $p_{t-1}-p_{t-2}$ (see Fig. 8), pairwise for different treatments. *, $* *$, and $* * *$ denote treatment comparisons when the null hypothesis of equality is rejected at the $10 \%, 5 \%$ or $1 \%$ significance level, respectively.

\section{C.6 Nonparametric test for discoordination comparison}

\begin{tabular}{l|ccccccc}
\hline Discoord & ConH1 & ConH2 & ConH3 & OscH1 & OscH2 & OscH3 & OscH3SF \\
\hline ConH1 & $\mathrm{X}$ & $0.021^{* *}$ & 0.320 & $0.086^{*}$ & $0.014^{* *}$ & $0.011^{* *}$ & $0.054^{*}$ \\
ConH2 & & $\mathrm{X}$ & 0.821 & 0.740 & $0.007^{* * *}$ & $0.066^{*}$ & 0.135 \\
ConH3 & & & $\mathrm{X}$ & 0.827 & $0.014^{* *}$ & 0.198 & 0.198 \\
OscH1 & & & & $\mathrm{X}$ & 0.107 & $0.080^{*}$ & 0.254 \\
OscH2 & & & & & $\mathrm{X}$ & $0.018^{* *}$ & 0.367 \\
OscH3 & & & & & & $\mathrm{X}$ & 0.810 \\
OscH3SF & & & & & & & $\mathrm{X}$ \\
\hline
\end{tabular}

Table 11: p-values of the two-sided Kolmogorov-Smirnov test comparing the discoordination (median of the standard deviations of predictions) statistics, pairwise for different treatments. ${ }^{*}, * *$, and ${ }^{* * *}$ denote treatment comparisons when the null hypothesis of equality is rejected at the $10 \%, 5 \%$ or $1 \%$ significance level, respectively.

\begin{tabular}{l|ccccccc}
\hline Discoord & ConH1 & ConH2 & ConH3 & OscH1 & OscH2 & OscH3 & OscH3SF \\
\hline ConH1 & $\mathrm{X}$ & $0.099^{*}$ & 0.111 & 0.167 & $0.005^{* * *}$ & $0.071^{*}$ & 0.128 \\
ConH2 & & $\mathrm{X}$ & 0.556 & 0.399 & $0.005^{* * *}$ & $0.100^{*}$ & $0.100^{*}$ \\
ConH3 & & & $\mathrm{X}$ & 0.464 & $0.012^{* *}$ & 0.259 & 0.294 \\
OscH1 & & & & $\mathrm{X}$ & $0.021^{* *}$ & 0.473 & 0.194 \\
OscH2 & & & & & $\mathrm{X}$ & 0.170 & 0.619 \\
OscH3 & & & & & & $\mathrm{X}$ & 0.539 \\
OscH3SF & & & & & & & $\mathrm{X}$ \\
\hline
\end{tabular}

Table 12: p-values of the Fischer-Pitman permutation test comparing the discoordination (median of the standard deviations of predictions) statistics, pairwise for different treatments. ${ }^{*}, * *$, and ${ }^{* * *}$ denote treatment comparisons when the null hypothesis of equality is rejected at the $10 \%, 5 \%$ or $1 \%$ significance level, respectively. 


\begin{tabular}{l|ccccccc}
\hline Discoord & ConH1 & ConH2 & ConH3 & OscH1 & OscH2 & OscH3 & OscH3SF \\
\hline ConH1 & $\mathrm{X}$ & $0.057^{*}$ & 0.200 & 0.133 & $0.036^{* *}$ & $0.024^{* *}$ & $0.048^{* *}$ \\
ConH2 & & $\mathrm{X}$ & 0.857 & 0.683 & $0.016^{* *}$ & $0.038^{* *}$ & 0.257 \\
ConH3 & & & $\mathrm{X}$ & 0.921 & $0.036^{* *}$ & $0.095^{*}$ & 0.381 \\
OscH1 & & & & $\mathrm{X}$ & $0.045^{* *}$ & 0.282 & 0.181 \\
OscH2 & & & & & $\mathrm{X}$ & $0.082^{*}$ & 0.792 \\
OscH3 & & & & & & $\mathrm{X}$ & 1.000 \\
OscH3SF & & & & & & & $\mathrm{X}$ \\
\hline
\end{tabular}

Table 13: p-values of the Mann-Whitney-Wilcoxon test comparing the discoordination (median of the standard deviations of predictions) statistics, pairwise for different treatments. ${ }^{*}, * *$, and $* * *$ denote treatment comparisons when the null hypothesis of equality is rejected at the $10 \%, 5 \%$ or $1 \%$ significance level, respectively.

\section{Dynamics of individual forecasts and price}

Figures 11-17 show the evolution of individual forecasts and prices (in black with markers) for each of the 35 groups of our experiment. Figures are organized by treatment, see captions for the details. The first ten periods in each panel show the initial price history in the group. The point forecasts are displayed against those time periods that they are made for (and not when they are made). For instance, in treatment ConH3, in period $t=15$, we show price $p_{15}$ and individual forecasts, $p_{i, 15}^{e}$ that were made in period 12 .
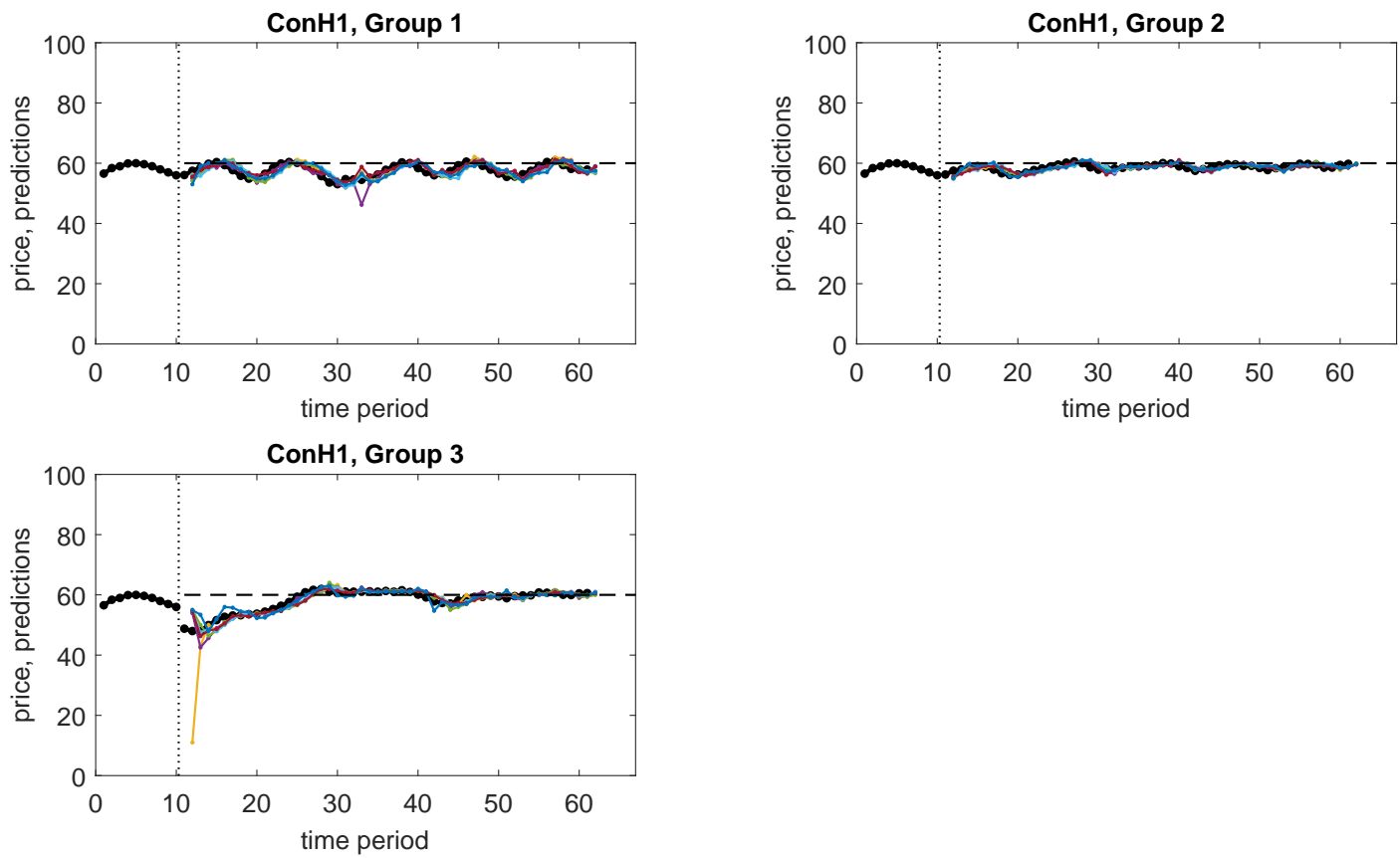

Figure 11: Forecasts and price dynamics (black) in the three groups of the ConH1 treatment. 

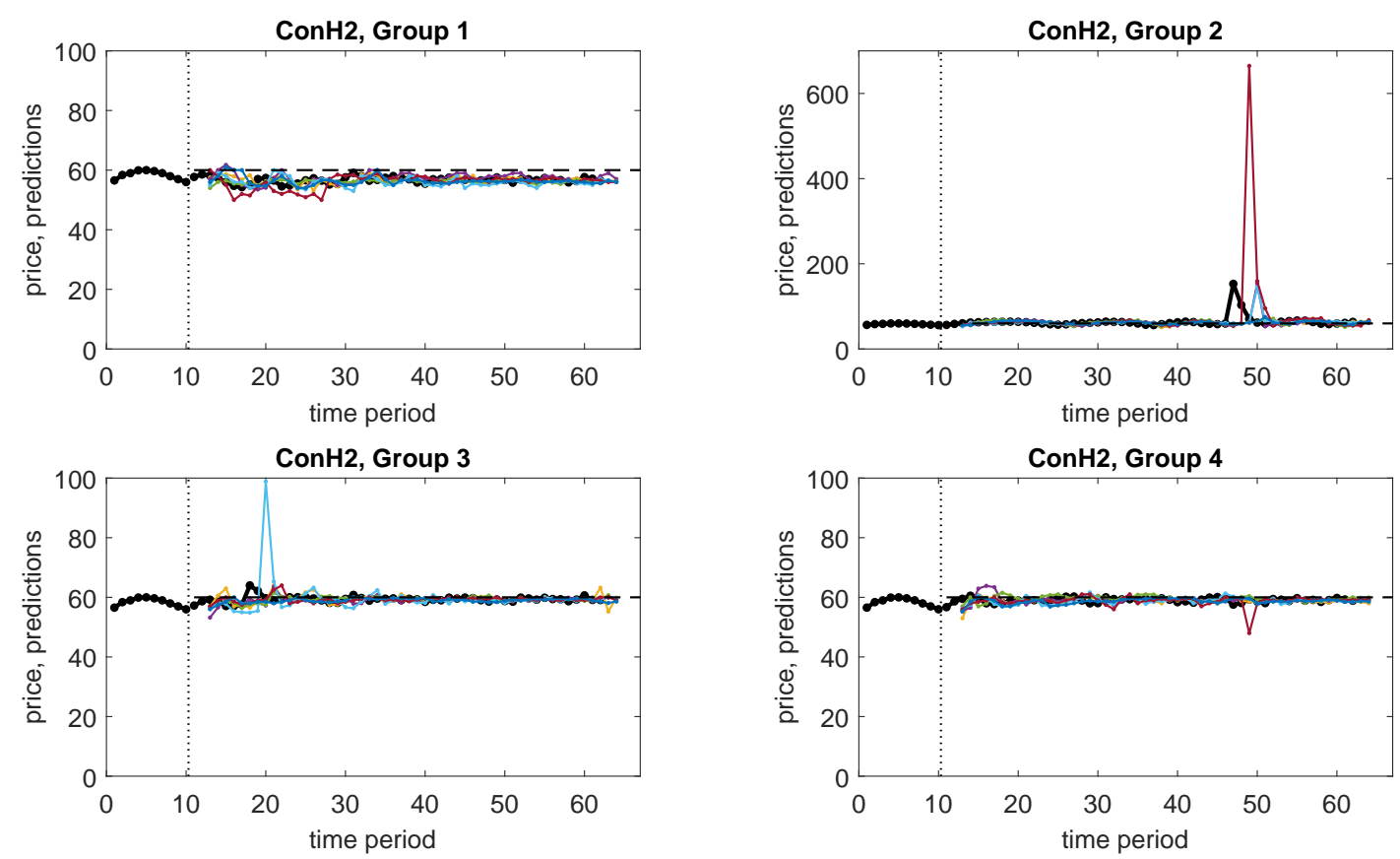

Figure 12: Forecasts and price dynamics in the four groups of the ConH2 treatment.
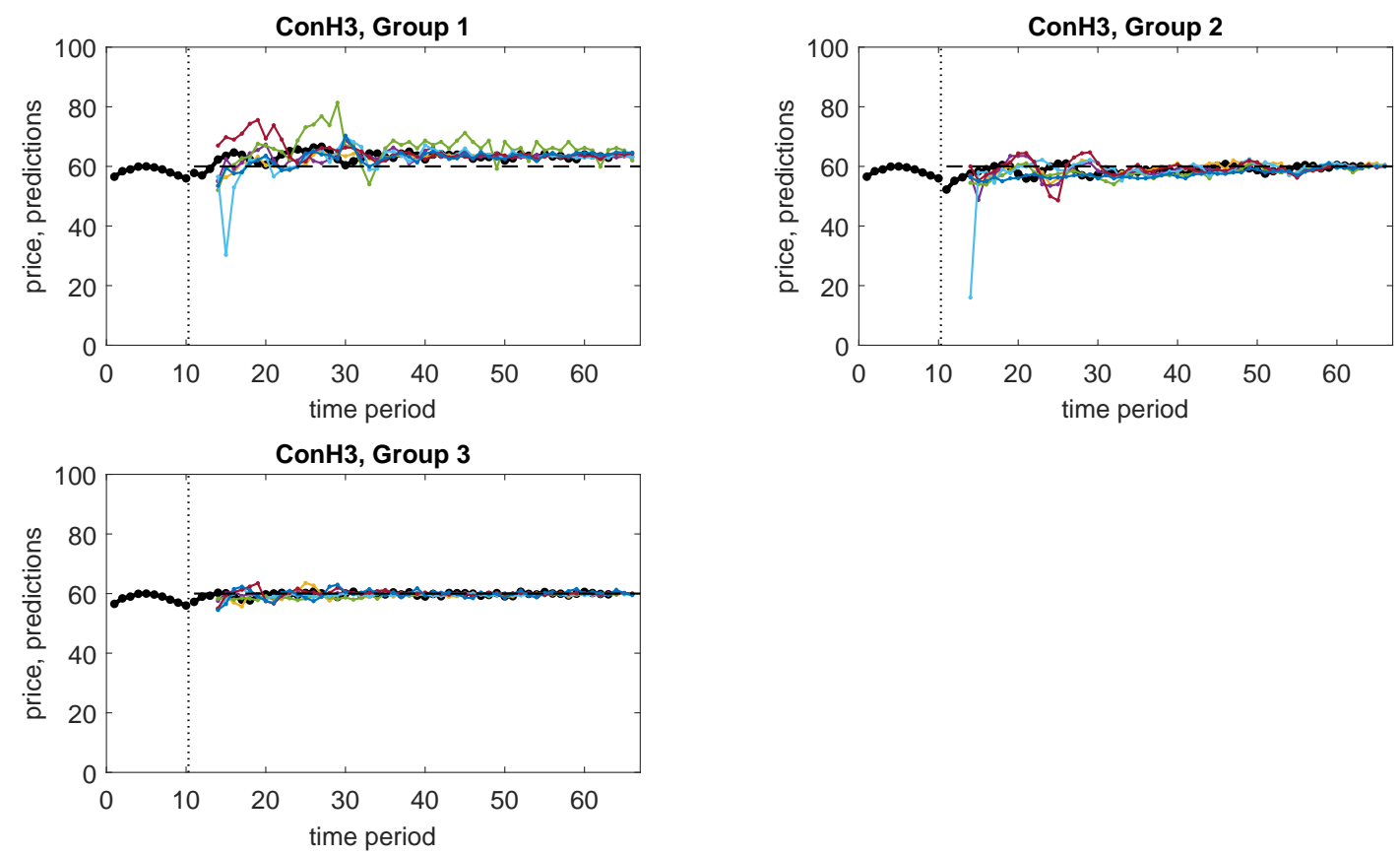

Figure 13: Forecasts and price dynamics in the three groups of the ConH3 treatment. 

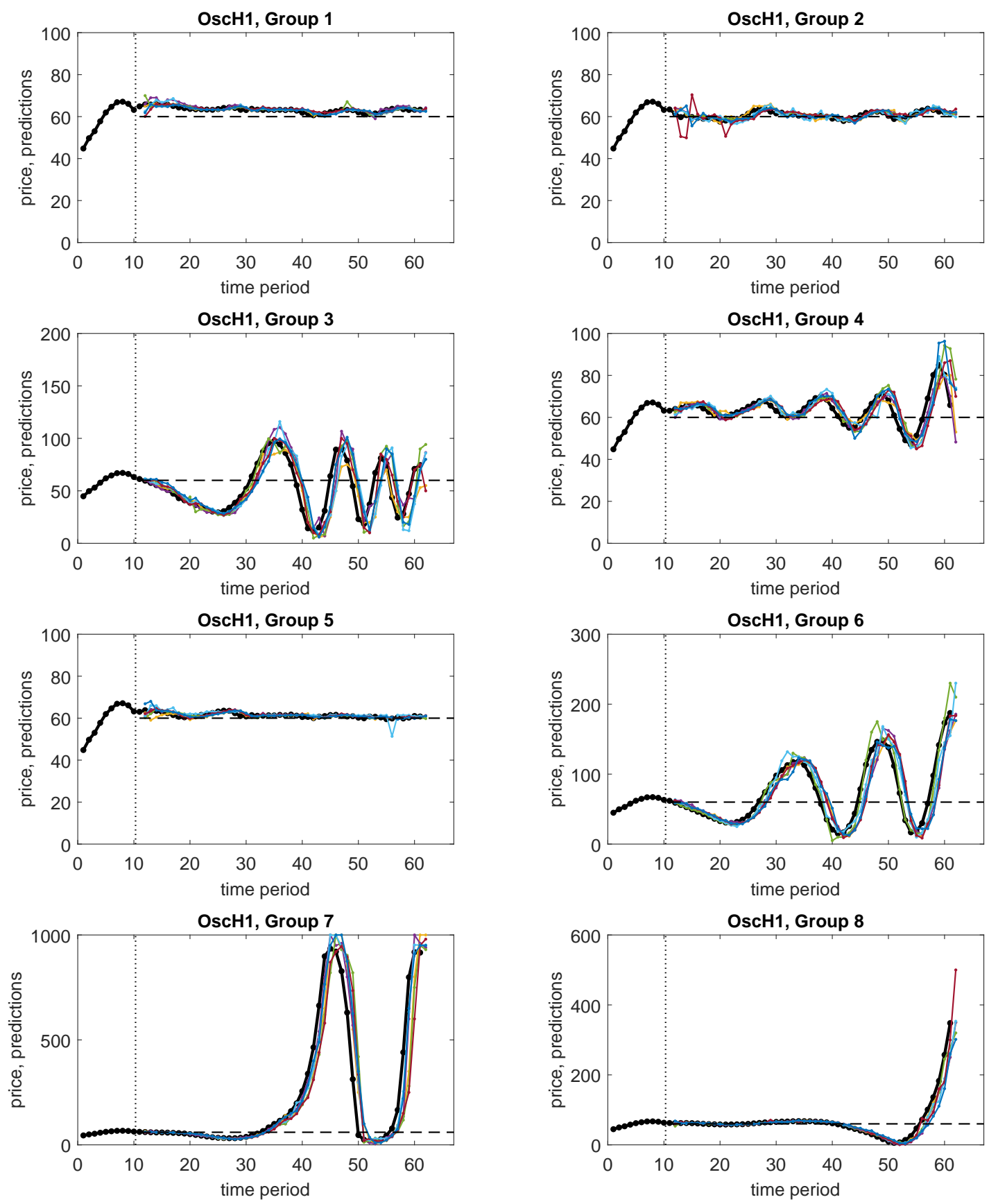

Figure 14: Forecasts and price dynamics in the eight groups of the OscH1 treatment. 

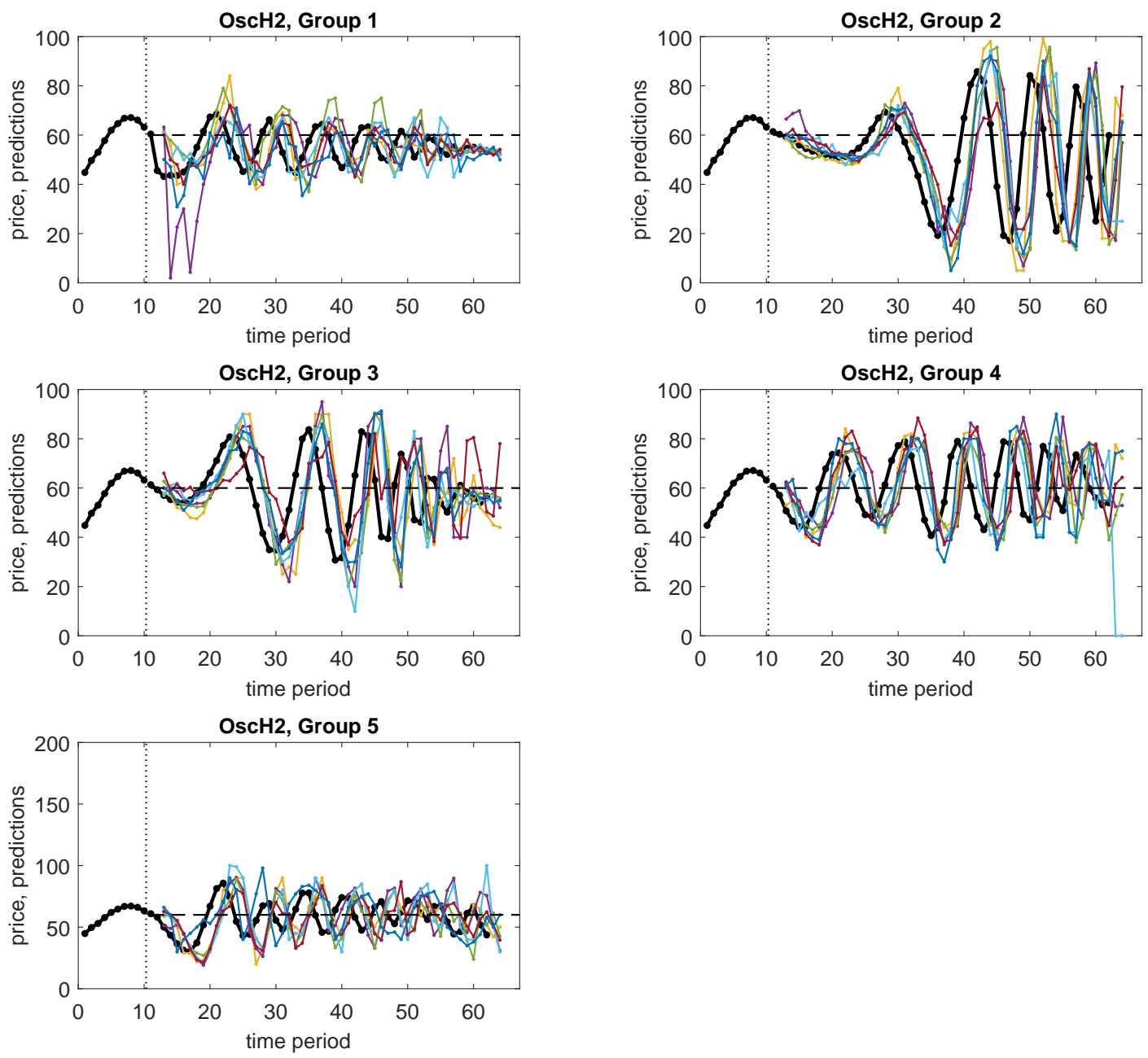

Figure 15: Forecasts and price dynamics in the five groups of the OscH2 treatment. 

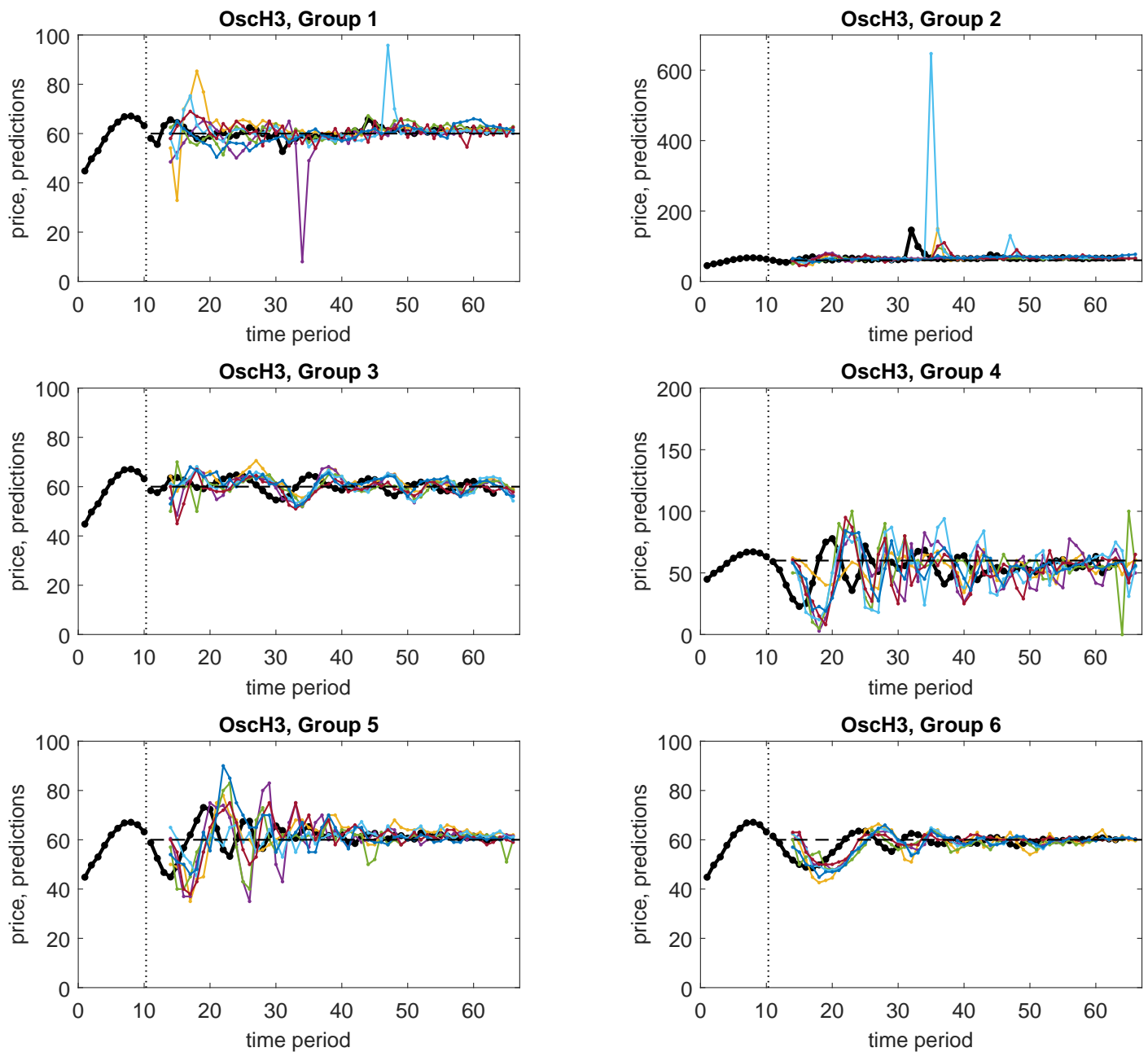

Figure 16: Forecasts and price dynamics in the six groups of the OscH3 treatment. 

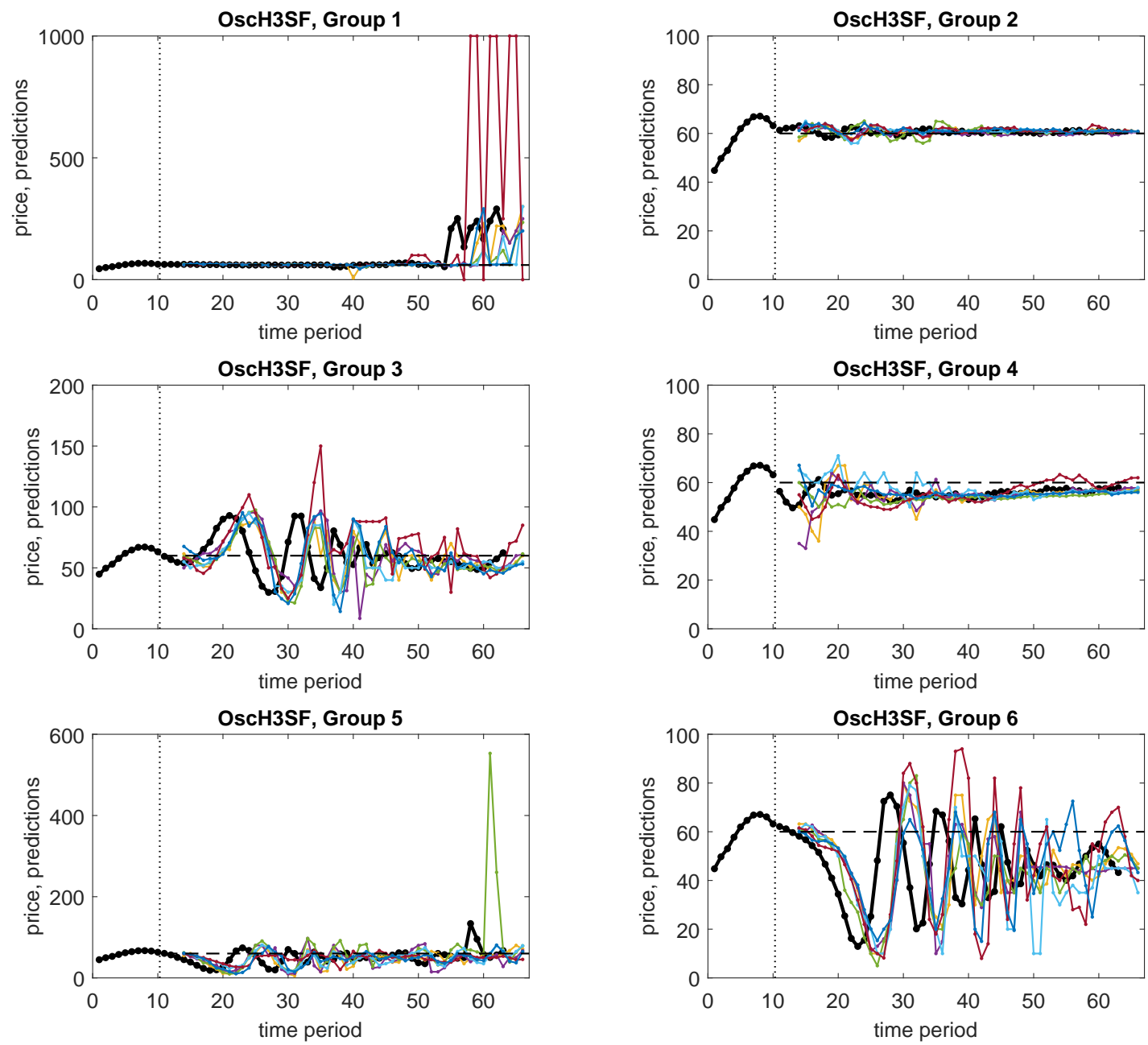

Figure 17: Forecasts and price dynamics in the six groups of the OscH3SF treatment. Note the abnormal behaviour of one of the participants in the last 10 periods in group 1, which significantly affected the price dynamics. We excluded the last 10 periods on this group from our analysis. 